\title{
"Combo" nanomedicine: Co-delivery of multi-modal therapeutics for efficient, targeted, and safe cancer therapy
}

\author{
Jessica A. Kemp ${ }^{1}$, Min Suk Shim ${ }^{2}$, Chan Yeong Heo ${ }^{1,3}$, Young Jik Kwon ${ }^{1,4,5,6^{*}}$ \\ ${ }^{1}$ Department of Pharmaceutical Sciences, University of California, Irvine, California, CA 92697, \\ ${ }^{2}$ Division of Bioengineering, Incheon National University, Incheon 406-772, Republic of Korea, \\ ${ }^{3}$ Department of Plastic Surgery, Seoul National University College of Medicine, Bundang, \\ Republic of Korea, ${ }^{4}$ Department of Chemical Engineering and Materials Science, University of \\ California, Irvine, California, CA 92697, ${ }^{5}$ Department of Biomedical Engineering, University of \\ California, Irvine, California, CA 92697, ${ }^{6}$ Department of Molecular Biology and Biochemistry, \\ University of California, Irvine, California, CA 92697 \\ * Corresponding author \\ 132 Sprague Hall \\ Irvine, CA 92697 \\ Tel: +1 9498248714 \\ Fax: +1 9498244023 \\ Email: kwonyj@uci.edu
}




\begin{abstract}
The dynamic and versatile nature of diseases such as cancer has been a pivotal challenge for developing efficient and safe therapies. Cancer treatments using a single therapeutic agent often result in limited clinical outcomes due to tumor heterogeneity and drug resistance. Combination therapies using multiple therapeutic modalities can synergistically elevate anti-cancer activity while lowering doses of each agent, hence, reducing side effects. Co-administration of multiple therapeutic agents requires a delivery platform that can normalize pharmacokinetics and pharmacodynamics of the agents, prolong circulation, selectively accumulate, specifically bind to the target, and enable controlled release in target site. Nanomaterials, such as polymeric nanoparticles, gold nanoparticles/cages/shells, and carbon nanomaterials, have the desired properties, and they can mediate therapeutic effects different from those generated by small molecule drugs (e.g., gene therapy, photothermal therapy, photodynamic therapy, and radiotherapy). This review aims to provide an overview of developing multi-modal therapies using nanomaterials ("combo" nanomedicine) along with the rationale, up-to-date progress, further considerations, and the crucial roles of interdisciplinary approaches.
\end{abstract}

Key words: Multi-modal therapy; nanomedicine; synergistic anti-cancer effects

Abbreviations: AuNC: Gold nanocage; AuNR: Gold nanorod; AuNS: Gold nanoshell; Bcl-2: Bcell lymphoma; BRAFi: BRAF inhibitor; BSA: Bovine serum albumin; CAFs: Cancer associated fibroblasts; CaP: Calcium phosphate; CAR: Chimeric antigen receptors; Chk1i: Checkpoint kinase 1 inhibitor; CI: Combination index; CNTs: Carbon nanotubes; CSCs: Cancer stem cells; DMA-C60: Diadduct malonic acid fullerene; DOX: Doxorubicin; DTX: Docetaxel; ER+: Estrogen receptor positive; EGCG: Epigallocatechin gallate; FA: Folic acid; FAP: Fibroblast activation protein; GFR: Growth factor receptor; Glu(CPT)-NCA: g-camptothecin-glutamate Ncarboxyanhydride; HAuNPs: Hollow gold nanoparticles; HCQ: Hydroxychloroquine; HP: Hematoporphyrin; ICI: Antiestrogen; MEKi : MEK inhibitor; Mcl-1: Myeloid cell leukemia 1; MCNPs: Mesoporous carbon nanoparticles, MDR: Multidrug resistant; NCP: Nanoscale coordination polymer; NGO: Nanographene oxide; NIR: Near-infrared light; NPs: Nanoparticles; OS: Overall survival; PCL: Poly-(e-caprolactone); PDT: Photodynamic therapy; PEG: Polyethylene glycol; PEI: Polyethyleneimine; PFS: Progression free survival; P-gp: Pglycoprotein; PI3Ki: PI3K inhibitor; PLGA: Poly(lactic-co-glycolic acid); PP2A: Protein phosphatase 2A; PTX: Paclitaxel; PVP: Polyvinylpyrrolidone; RES: Reticuloendothelial system; RNAi: RNA interference; ROS: Reactive oxygen species; siRNA: Small interfering RNA; SPR: Surface plasmon resonance; SWNT: Single walled carbon nanotubes; TAM: Tamoxifen; TME: Tumor microenvironment; TAMS: Tumor associated macrophages; TKI: Tyrosine kinase inhibitor 


\section{Introduction}

Cancer treatments have been significantly refined due to an increased awareness of the molecular, cellular, and physiological mechanisms involved in the initiation and progression of the disease [1]. Chemotherapy is one of the most commonly utilized cancer treatment methods, and it is often accompanied by systemic side effects mainly attributed to nonspecific drug accumulation [2]. As a result, chemotherapy patients often suffer adverse side effects associated with overdose because safe dosages may not completely eradicate tumors [3]. Combination therapy seeks to increase cancer eradication efficacy without amplifying systemic toxicity while simultaneously overcoming drug resistance [4]. In order for this to be accomplished, the therapeutics must synergistically work on different but inter-related oncogenic signal transduction pathways. Therefore combination therapies can be used in order to enhance therapeutic efficacy and decrease drug resistance by targeting a single oncogenic pathway through different modes of action or across multiple interrelated pathways.

One of the greatest challenges to successfully treating cancer is intratumoral genetic heterogeneity [5]. Clonal heterogeneity drives cancer progression and metastasis, and can dynamically affect the biology of the tumor as a whole [6]. Furthermore, the genetic diversity in solid tumors often results in temporary, limited responses to chemotherapeutics, which allow for various mechanisms of resistance to form [7]. Resistance mechanisms often alter the addiction pathway to allow for cancer to thrive through the initial oncogenic route and include bypass measures where a parallel signaling pathway is activated [8]. Combination therapies can serve to counter these resistance mechanisms by concurrently targeting multiple components in a single pathway or across parallel pathways. The co-delivery of multiple drugs can modulate the genetic barriers responsible for cancer cell mutations and can suspend the cancer adaptation process.

It is crucial to carefully consider the vast complexities of signaling pathways and the genetic diversity of each cancer when combination therapies are developed. Determining a truly synergistic therapy regimen requires in-depth evaluation of these pathways. High-throughput screening has provided a highly effective method to determine successful combinatorial therapies [9]. Likewise, screening tumor cells for loss/gain of function across the genome leads to the identification of critical silencing or over-expression involved in drug resistance [10]. Another key consideration in combination chemotherapy is the pharmacokinetic profiles of the 
drugs and more specifically, optimizing the combination and delivery mechanism. Nanotechnology serves to advance cancer therapy by co-delivering multiple payloads, enhancing transport properties, improving biodistribution, normalizing accumulation, and optimizing release profiles $[11,12]$.

The development of enhanced transport systems has revolutionized the approach to improving chemotherapy, and the field of nanotechnology is helping to pave the way [13-15]. Through the utilization of various nanoformulations, many of the issues associated with the use of free drugs have been addressed via tunable release of therapeutics, enhanced pharmacokinetic and pharmacodynamics profiles, modifications for superior targeted delivery, and ease of incorporation of multiple agents with differing solubility profiles [16-18]. Tunable release has been a major component of the recent boom in nanomedicine research, as stimuli-responsive carriers are optimized to release payload only upon certain cues either intracellularly or within the microenvironment of tumors and can potentially lower systemic toxicity of chemotherapeutic agents [19-21]. Commonly utilized triggers for payload release include a slightly acidic $\mathrm{pH}$ in the microenvironment, overexpression of specific enzymes, localized hyperthermia, and increased levels of glutathione within the cell [22-27]. Moreover, heightened control over release has grand implications on rational combinatorial therapies since co-delivery does not always imply simultaneous release, and ordered release of multiple therapeutic agents may achieve maximally synergistic effects [28-30].

The question arises whether co-formulated chemo-combination treatments will be enough to surmount drug resistance and genetic mutations. With the dynamic, complex nature of cancer, constantly re-routing to new pathways or altering existing ones, it seems resistances may eventually form against combinatorial treatments and cancer will persist. However, physical destruction in combination with agents can achieve cancer cell destruction by several different modes on alternative survival pathways and increases the likelihood of cancer eradication [31, 32]. Use of external stimuli such as near-infrared light, ultrasound, radiation, and magnetic fields can provide an alternative method of cancer treatment with the proper nanomaterials while simultaneously releasing payload only within target regions [33, 34]. Multi-modal cancer therapy utilizing chemotherapy and multifunctional nanomaterials has been shown to significantly increase the efficacy of a cancer treatment and potentially offers a better solution for overcoming 
resistance to chemotherapeutic agents $[35,36]$. This review seeks to explore some present challenges of tumor heterogeneity and resistance, benefits of combinatorial treatments, and focus on utilizing advanced nanomaterials to combat cancer from all possible angles.

\section{Rationale for Combination Therapy}

\subsection{Challenge: Drug resistance and the role of tumor genetic diversity}

The emergence of next generation sequencing marked the dawn of personalized medicine and has enabled the development of targeted therapies that can potentially overcome drug resistance that is either present prior to treatment (intrinsic resistance) or in adaptation to treatment (acquired resistance) [37]. The genetic diversity in solid tumors often results in temporary responses to chemotherapeutics, followed by resistance through various mechanisms [38].

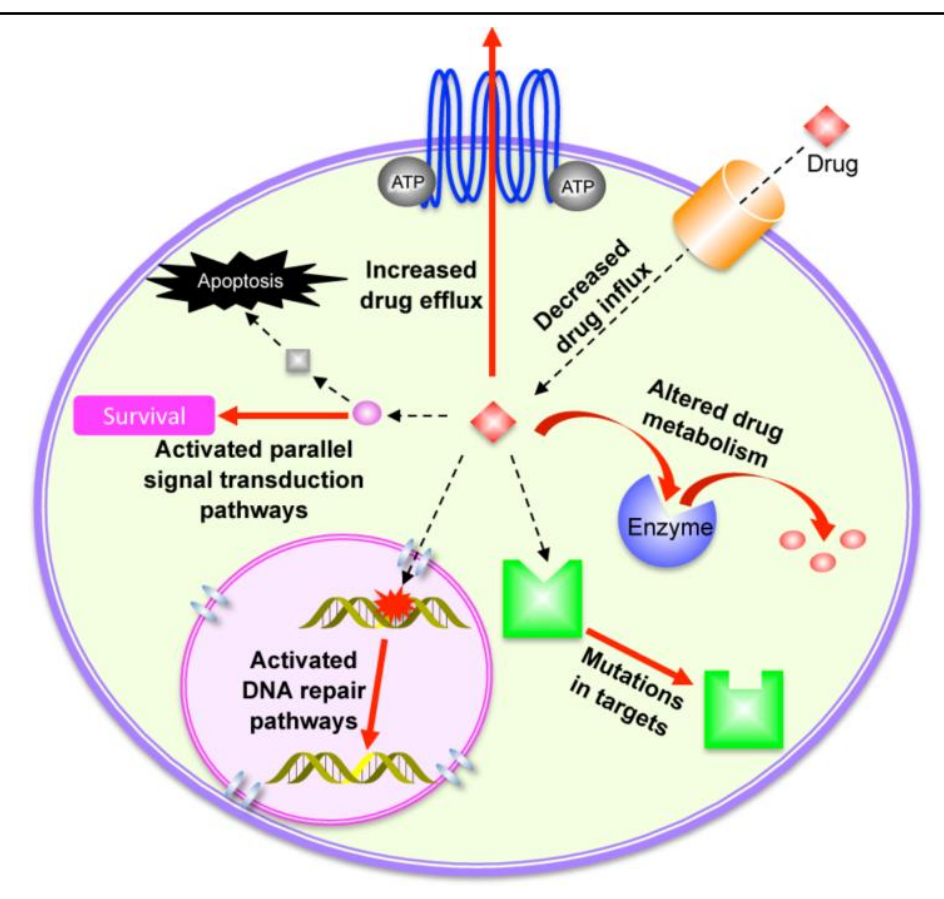

Figure 1. Various mechanisms through which cancer cells gain drug resistance include: lowered intracellular concentrations of therapeutics by activated drug efflux pumps and mutations in drug influx pumps, ineffective treatment upon mutations in drug targets, reversed destructive effects of chemotherapeutics via activated DNA repair pathways, and activation of parallel signaling pathways to compensate for inhibited pathways.
Intratumor heterogeneity generally enables drug resistance through an adaptive response at the cellular level, however alterations in the microenvironment of a tumor that limit drug absorption and/or delivery may also play a role [39-41]. In the former case, drug resistance may develop through several different routes: inactivated chemotherapeutics within the cell, changes in drug efflux/influx (severely impacting the intracellular drug concentration), activated repair pathways for reversed drug effects, vitalized parallel signal transduction pathways counteracting the drug action, and mutated drug targets 
rendering the drug ineffective (Figure 1) [42-46]. Resistance mechanisms can be overcome through the usage of combinatorial agents concomitantly tackling various routes of cell survival (e.g., cell metabolism) to synergistically kill cancerous cells. For example, a new metabolic analysis indicates that ovarian cancer may be susceptible to multidrug cocktails, particularly if the amounts of the drugs can be tailored to match the metabolic profile of a patient's tumor [47]. By measuring the ratio of glutamine amounts externally taken in to internally produced, prognosis could be determined, in that a high ratio directly correlated to tumor aggression and metastasis. Using a multidrug combination therapy of a glutaminase inhibitor with a STAT3 inhibitor, cell proliferation significantly decreased.

Re-routing of signal transduction pathways in response to therapy and selection of resistant subclones are two main components of acquired resistance [48-50]. At any given time, the degree of clonal diversity may be an indicator of risk for further disease progression depending upon the variation of subclones (Figure 2) [51-54]. Cancer chemotherapeutics often initiate directional selection, and the mechanisms of resistance may vary depending upon the drug target [54-56]. While it is speculated that single targeted therapies may not be enough to surmount the dynamic nature and adaptive capacity of tumor cells [57], rational combinatorial therapies have the potential to overcome these resistance mechanisms with additional advantages such as blocking multiple survival pathways. It was recently found that as drug resistance occurs, tumor cells acquire stem cell-like properties giving them the capacity to survive throughout the body

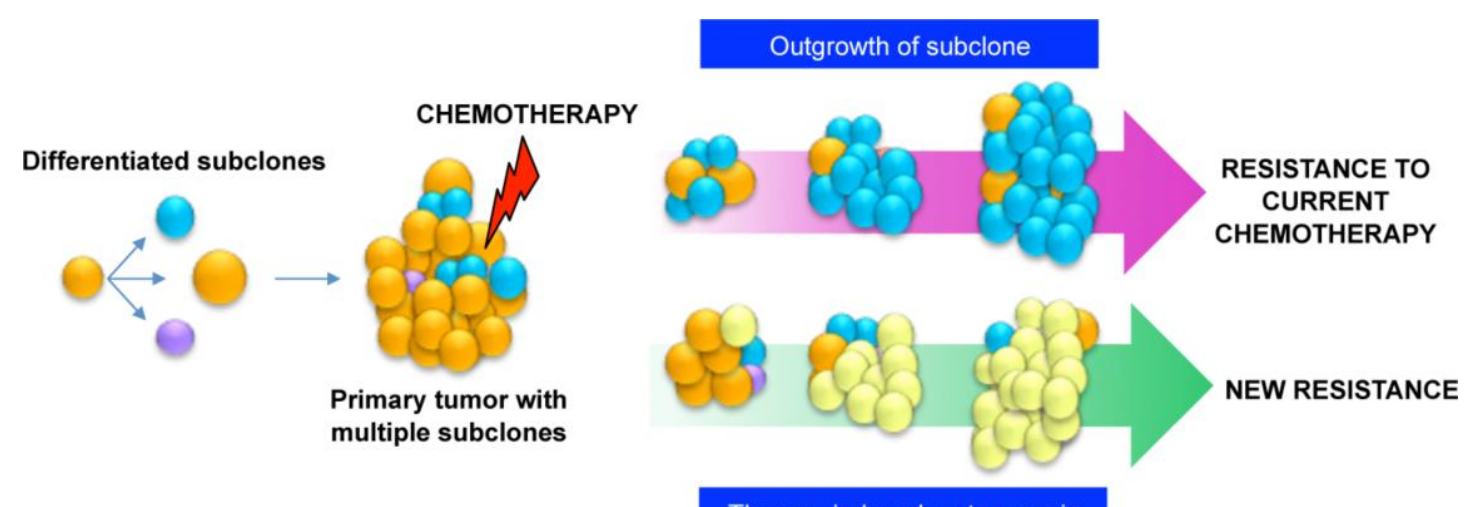

Therapy-induced mutagenesis

Figure 2. Drug resistance led by heterogeneity within a primary tumor through an evolutionary response to the treatment and/or mutations originating from the therapy. Chemotherapy may lead to an outgrowth of a subclone that is non-responsive to the treatment, and depending on the type of therapeutic, may induce mutations that result in resistance to other treatments as well. 
and essentially ignore the drugs [58]. For example, in a study on acquisition of resistance against tyrosine kinase inhibitors (TKIs), the molecular pathway that facilitates pluripotency of tumor cells and drug resistance was delineated, and existing drugs that exploit this pathway (e.g., bortezomid) were identified. Bortezomid not only reversed stem cell-like properties of tumors, but also appeared to re-sensitize erlotinib-resistant tumors. Treatments based solely upon resistance-conferring mutations are insufficient due to the complex dynamics and heterogeneity of cancer. Targeting a subclonal driver mutation could also cause an acceleration of growth in other clones. For example, BRAF, KRAS, and NRAS mutations can be subclonal in multiple myeloma, and the use of BRAF inhibitors can activate ERK signaling in BRAF wild-type cells [59]. A computational prediction used to optimize therapeutics combinations specifically to treat tumor heterogeneity found that knowledge of the dominant subclones alone is often insufficient for selecting certain drug combinations. Additionally, it is not always the case that the optimal combination will be comprised of drugs that are known to be the most effective against specific subpopulations. Not only high levels of heterogeneity in a tumor, but also distinct profile differences in patients make monotherapies more and more challenging. Knowing that further mutations may render the treatment ineffective, it may be more costly, in regards to both time and money, to develop personalized medicine targeting specific tumor subclones. Instead, multimodal treatments could be a more plausible and reliable solution to overcome drug resistance and tumor heterogeneity.

\subsection{Simultaneously targeting major oncogenic pathways by multiple chemotherapuetics}

Chemotherapy continues to be the first-line treatment for most cancers, and more targeted therapeutics are moving forward in research and clinical application [2, 37, 60]. The coadministration of classic cytotoxic agents with those specifically targeting enzymes in the cancer addiction pathways has shown promise in the clinical setting [61-64]. Combination therapies using two or more therapeutic agents targeting specific pathways can synergistically eradicate cancer and halt tumor growth, however certain combinations may be more detrimental or quality of life may decrease despite an increase in survival time $[65,66]$. There are currently hundreds of combination therapies undergoing clinical evaluation, and Table 1 lists several examples of recently completed Phase III clinical trials [67-77]. Targeting multiple constituents within a 


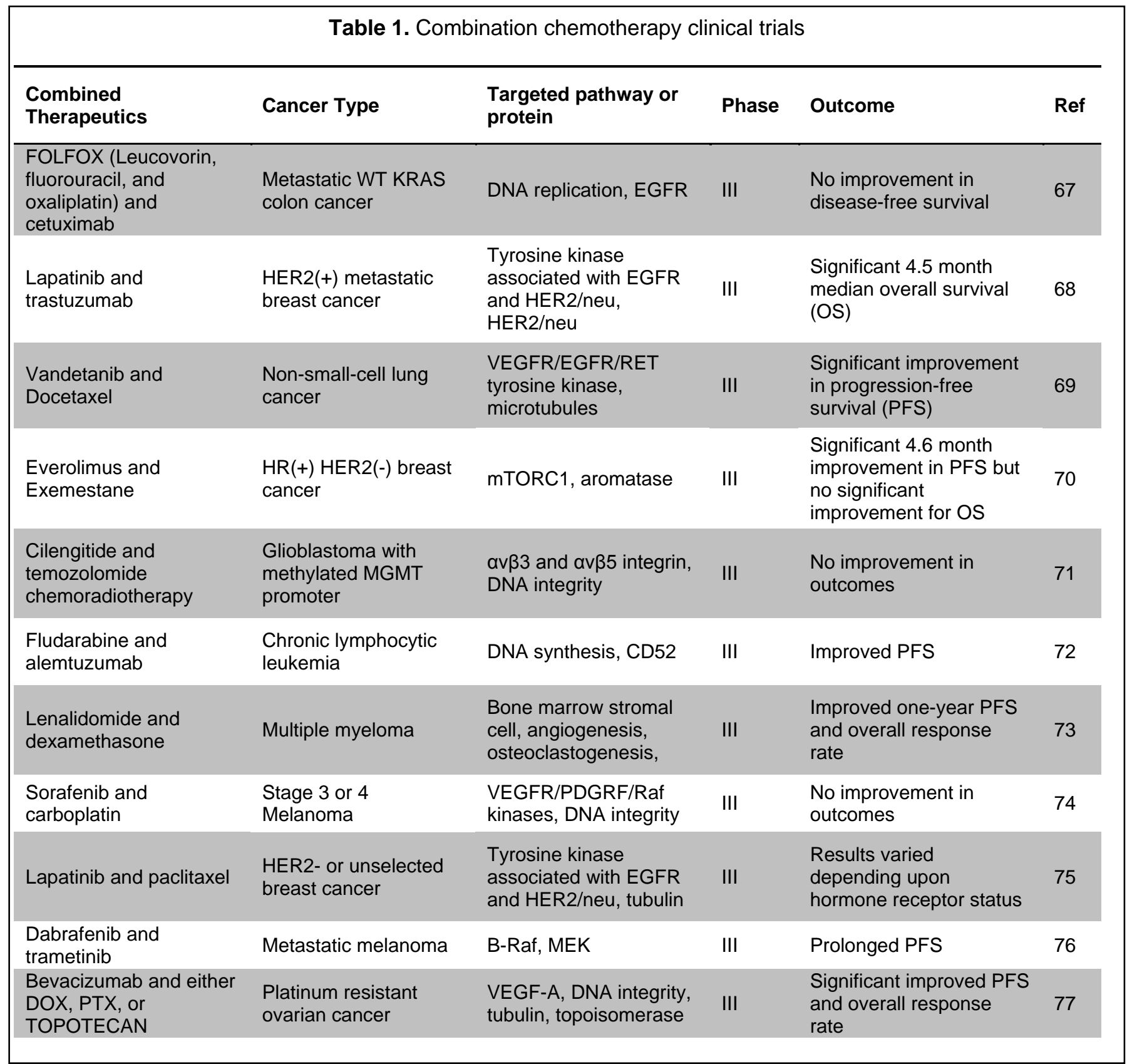

single pathway may allow for a maximum inhibition of that particular signaling network, possibly even a complete shutdown [78, 79]. However, parallel pathways rescuing the inhibited pathway could be activated, and combinatorial treatment may be used in this case as well [8].

The key signaling networks that promote and sustain cancer (e.g., RAS/RAF/MEK/ERK and $\mathrm{PI} 3 \mathrm{~K} / \mathrm{Akt} / \mathrm{mTOR}$ pathways) hold significant targets for combination treatments, and a plethora of inhibitors have been developed for enzymes within these pathways [80]. Monotherapies often fail over time due to the prevailing mutations common to components in the key signaling 
pathways and their interchangeable nature [81], making combination therapy nearly a necessity. RAS is the most commonly mutated oncogene, and direct KRAS inhibition has been unsuccessful without co-treatment with additional therapeutics [82]. Mutations in endothelial growth factor receptors (EGFRs) and their overexpression are major contributing factors to oncogenesis and tumor growth/proliferation [83-86]. Use of combination, EGFR-targeting therapies is gaining headway due to increased resistance to EGFR-targeted monotherapies in lung, head and neck, and colorectal cancers [87, 88]. Upregulated VEGF/VEGFR expression is frequently found in tumor tissue, but VEGF antibodies and VEGFR-TKIs have limited antitumor efficacy as monotherapies and are enhanced by co-treatment with other therapeutics [89]. Conversely, conventional chemotherapy is typically associated with upregulation of VEGF/VEGFR expression so concomitant administration of classic chemotherapeutics with antiangiogenic agents seems justified [90].

Cell proliferation, differentiation, and development are all initiated within the RAS/RAF/MEK/ERK pathway, thus it often sustains multiple mutations in various cancer types [91]. MEK1/2 inhibitors used with EGFR or VEGFR TKIs have demonstrated growth inhibition, anti-angiogenesis, and curbed metastasis. Resistance to a BRAF inhibitor (BRAFi) dabrafenib, attributed to mutations in NRAS or MEK, was restored when melanoma cells were co-treated with dabrafenib and a MEK inhibitor (MEKi) trametinib [92, 93]. This combination treatment was subsequently approved by the FDA in 2014 for therapy for advanced melanoma. Inhibition of the BRAF (V600E) oncoprotein in colon cancers was shown to cause continued proliferation due to rapid feedback-triggered EGFR activation, and combination therapy consisting of BRAF and EGFR inhibitors demonstrated high synergism both in vitro and in vivo [94]. It was found that BRAFi induce metastasis in RAS mutant melanoma cells or BRAFi-resistant melanoma cells through stimulating MEK and ERK signaling. By combining BRAFi with MEKi, the induced metastasis was prevented [95, 96]. Multiple myeloma cells are often able to survive by increasing Mcl-1 production, causing high resistance levels to bortezomib, a proteasome inhibitor commonly used for relapsed multiple myeloma patients [97]. A novel drug combination of a checkpoint kinase 1 inhibitor (Chk1i) with a MEKi effectively reduced Mcl-1 expression [98]. Exposing multiple myeloma and leukemia cells to Chk1i activated a protective response to through the Ras/MEK/ERK signaling pathway. Chk1i prevent cells from arresting in stages of the cell cycle that facilitate the repair of DNA damage, while MEK inhibitors prevent cells from 
activating a variety of proteins that regulate DNA repair processes and promote the accumulation of pro-apoptotic proteins [99].

Multiple mechanisms in PI3K/Akt/mTOR pathway are often hyper activated in many cancers for protein synthesis, cell survival and proliferation, and glucose metabolism, necessitating targeted combination therapies against adaptive resistances in the pathway [100-102]. Combination therapies using multiple PI3K/Akt/mTOR pathway inhibitors have been extensively evaluated both in the clinical setting and pre-clinical studies and resulted in greatly varying antitumor efficacies [103-106]. For example, co-treatments targeting HER2 and mTOR demonstrate high efficacy, whereas co-inhibition of EGFR and mTOR did not. PI3K inhibitor (PI3Ki) resistance in breast cancer xenograft models was overcome by combination of PI3Ki and CDK4/6 inhibitors with effectively constrained tumor growth [107]. The study also suggested that the combination may be synergistic in different genomic backgrounds and can block the multiple cyclinD1- and CDK4-activating mechanisms for inhibited growth and proliferation of PI3Ki resistant cells. Simultaneous co-inhibition of RAS/RAF/MAPK and PI3K/AKT/mTOR pathways has emerged as a popular scheme for combination therapy [108-110]. Targeting these two pathways may be particularly effective in cancers attributed to mutations in PI3K and either KRAS or BRAF [108]. In ovarian clear cell carcinoma, inhibition of a downstream target of mTOR and HIF-1 activated the RAS pathway via MEK phosphorylation, and combination therapy using inhibitors of MEK and mTOR simultaneously synergistically eradicated HIF-1 $\alpha$-silenced cells [111].

Multiple inhibitions within a single pathway can be upended once the cancer cell switches to an alternative pathway, so, combination therapies targeting parallel pathways may be the optimum approach. Another tactic is preventing cross talk between multiple growth factor receptors (GFRs). For example, two new tetra-specific antibodies recognizing EGFR, HER2, HER3, and VEGF inhibited multiple receptor signaling both in vitro and in vivo [112]. Additionally, crosstalk between HER and MET pathways was disrupted with higher efficacy than bispecific antibodies in multiple tumor models. The extensive degree of cross-talk between EGFR and VEGFR pathways found in cancer make them a promising target for combination therapies [113].

\subsection{Targeting constituents within the tumor microenvironment}


In addition to the major intracellular oncogenic pathways, the tumor microenvironment (TME) consists of key components contributing to tumor growth and proliferation such as various immune and inflammatory cells, blood and lymphatic endothelial cells, cancer associated fibroblasts, and bone marrow-derived mesenchymal stem cells [114]. Targeting these factors has become a focal point in developing new drug therapies and improving upon existing treatments such as VEGF-dependent antiangiogenic agents which have moderate impact as monotherapies [115]. Formation of new blood vessels to fuel tumor growth depends upon the interaction of the cancer cells with the TME angiogenic components, i.e. fibroblast growth factor, angiopoietins, placental growth factor, inflammatory cells, and matrix metalloproteinases [116-120]. Serum angiopoietin-2 was recently shown to induce resistance to VEGF inhibitors in differentiated thyroid and endometrial cancer, and combination therapy consisting of lenvatinib and golvatinib to target VEGFR1-3 and angiopoietin-2, respectively, demonstrated effective inhibition of pericyte network development [121].

Inflammation has been directly linked to various cancers as having a causative effect $[122,123]$. Inflammatory responses to exposures of p53-activating chemotherapeutic drugs were measured in immune cells from the blood and lungs of healthy volunteers [124]. Various pro-inflammatory genes had enhanced expression after exposure to the chemotherapeutics which required both p53 and $\mathrm{NF}-\kappa \mathrm{B}$. Depending on the microenvironment, the secretion of these factors have distinct effects such as promoting inflammation in normal tissues upon injury and modifying cancer cell responses in the tumor microenvironment. It was suggested that systemic treatment with p53activating chemotherapeutics might enhance antitumor responses of normal macrophages without augmenting pro-tumor functions of tumor associated macrophages (TAMS). The hypoxic nature of the TME determines the types of inflammatory cells that infiltrate, typically favoring those that depend on the glycolytic pathway for survival $[125,126]$. Certain phenotypes of the TAMS and neutrophils are largely associated with promoting tumor cell growth, and NF$\kappa \mathrm{B}$ signaling plays a key role in controlling these phenotypes [127]. Furthermore, NF- $\kappa \mathrm{B}$ activation in infiltrating leukocytes results in a pro-inflammatory cytokine cascade that drives cell proliferation [126], making it a desirable candidate for drug targeting [128]. Protein kinase CK2 inhibitor CX-4945 was shown to inhibit NF- $\kappa$ B and AKT pro-survival signaling in human head and neck squamous cell carcinomas cell lines and xenograft models while simultaneously 
enhancing activation of the ERK-AP-1 signal pathway [129]. While CX-4945 alone showed modest anti-tumor activity, combination with MEK inhibitor PD-901 demonstrated enhanced anti-tumor activity in vivo. However, it is important to recognize that immune deficiency from prolonged NF- $\mathrm{B}$ inhibition can cause severe side effects as well [130].

Cancer-associated fibroblasts (CAFs) are a subpopulation of cells within the TME known to promote angiogenensis, tumorigenecity, and metastatic dissemination of cancer cells [131]. Furthermore, CAFs express fibroblast activation protein (FAP), a type II transmembrane protein that is overexpressed in over $90 \%$ of CAFs associated with colon, breast, and lung carcinomas [132]. Poor intratumoral uptake of chemotherapeutic agents has been associated with expression and organization of collagen type 1, which is mainly produced by FAP [133], and treatment with anti-FAP antibodies or siRNA against FAP has shown to suppress pro-tumorigenic activity [134]. An oral DNA vaccine targeting FAP suppressed primary tumor cell growth and metastasis, decreased collagen type I expression, and increased drug uptake by 70\% [135]. In pFAP-vaccinated mice, there was a 3-fold prolonging of lifespan and significant tumor growth suppression, demonstrating the efficacy of combining chemo- and immunotherapies to fight cancer. Cancer stem cells (CSCs) are an attractive target for combination therapy as well, since CSCs reside within specific niches and contribute to tumor relapse and drug resistance [136, 137]. Various CSC properties such as metabolism, TME interactions, epigenetic states, quiescence, self-renewal, lack of differentiation, quiescence, and deregulation of apoptotic/survival pathways have been exploited to synergistically enhance chemotherapy through combination therapy [138]. For example, targeting the developmental pathway associated with tumor type pathogenesis, Hedgehog pathway, boosted efficacy of TKI inhibitor Imatinib while increasing survival time in a chronic myeloid leukemia murine model [139].

\subsection{Considerations for Effective Combinations}

By tackling multiple targets, combinatorial treatments aim to improve the therapeutic index either through increased efficacy and overcoming resistance or through similar efficacy with reduced systemic toxicity. In order to construct an effective combination therapy, the pharmacokinetics of each therapeutic agent must be investigated along with the biology of the target tumor. Most importantly, the combination of multiple therapeutic agents must generate a 


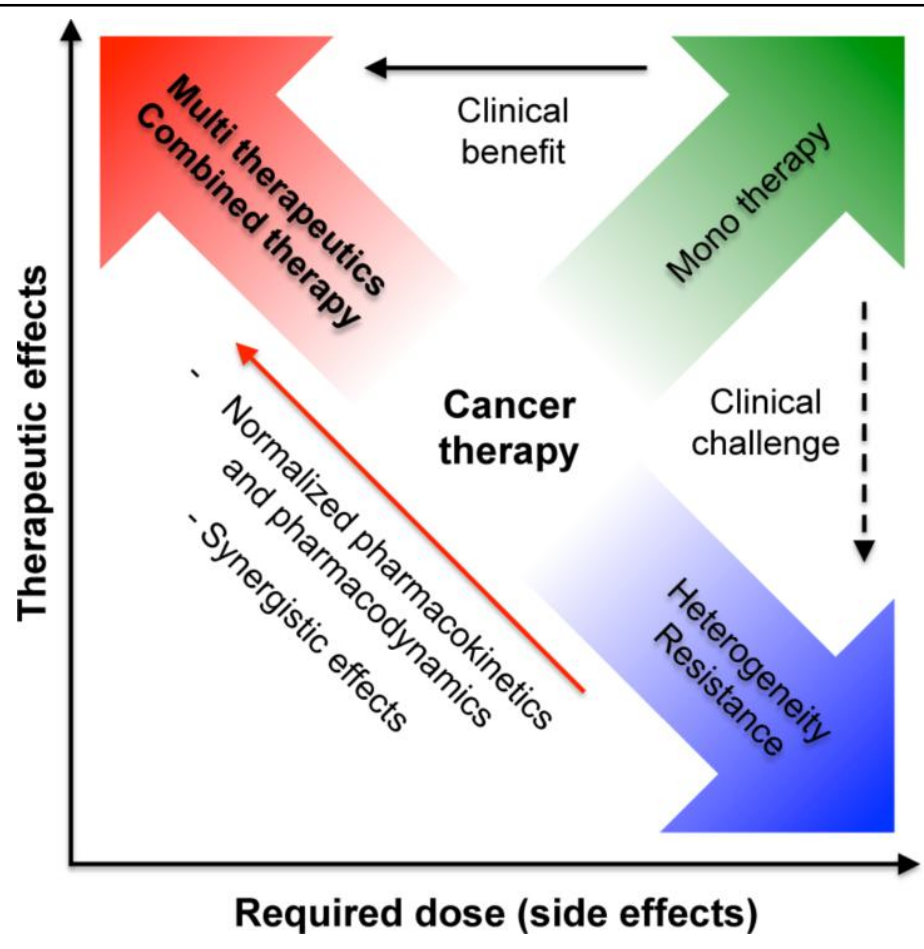

Figure 3. Tumor heterogeneity and resistance formation, two major obstacles found in cancer treatment development, challenge treatments using a single therapeutic agent. Combination therapies are clinically beneficial due to synergistic effects of lowering the required dose, hence side effects, and increasing therapeutic efficacy. synergistic effect, ideally at lower doses than typical doses of each individual compound (Figure 3) [140,141]. Two drugs are synergistic when the combinatorial efficacy is greater than that of the sum of the individual agents. The combination index (CI) and median effect equation (Equations 1 and 2, respectively) are two mathematical indicators for drug synergy, more accurate than a simple efficacy summation [141, $142,143]$.

$$
\mathrm{CI}=\left(\mathrm{D}_{\mathrm{A}} / \mathrm{D}_{\mathrm{x}, \mathrm{A}}\right)+\left(\mathrm{D}_{\mathrm{B}} / \mathrm{D}_{\mathrm{x}, \mathrm{B}}\right)
$$

where $D_{\theta}$ and $D_{x, \theta}$ represent concentration of drug used in combination to achieve $x \%$ effectiveness and concentrations of single drug to achieve $\mathrm{x} \%$ drug effect, respectively.

$$
\left(f_{a}\right) /\left(f_{u}\right)=\left[(D) /\left(D_{m}\right)\right]^{m}
$$

where $f_{a} / f_{u}, D, D_{m}$, and $m$ represent fraction affected/fraction unaffected, dose, median-effect dose, and kinetic order, respectively. Merging the median effect equation with the CI equation led to the quantitative definitions for analyzing drug synergism, where CI of less than, equal to, and more than 1 indicates synergy, additivity, and antagonism, respectively [141]. Corresponding doses to each effect level can be used to determine whether combinations are synergistic $(\mathrm{CI}<1)$, antagonistic $(\mathrm{CI}>1)$, or additive $(\mathrm{CI}=1)$. Synergy analysis is critical in determining proper therapeutics combination to avoid additive effects, in which case systemic 
toxicities typically increase [144]. Confirming and understanding a truly synergistic therapy regimen requires in-depth evaluation of the cancer-driven pathways and their individual components. $17, \mathrm{~s}$ of therapeutic agents must be optimized based upon quantitated synergy with each other [145]. Three different drug combinations taken from various drug classes (irinotecan/floxuridine, cytarabine/daunorubicin, and cisplatin/daunorubicin) were evaluated for ratio-dependent synergy. It was found that only specific drug ratios (1:1, 5:1, 10:1, respectively) yielded in vitro synergy, otherwise the interactions were deemed additive or antagonistic [146].

Simultaneous administration of multiple drugs with different molecular targets can modulate the genetic barriers responsible for cancer cell mutations, suspending the cancer adaptation process [147]. Effective combinations may often be found when one drug can serve to heighten or reintroduce sensitivity of the cancer cells to an existing therapy. For example, effective therapy for advanced, postmenopausal estrogen receptor-positive $(\mathrm{ER}+)$ breast cancer, a subtype accounting for approximately $70 \%$ of all breast cancers, can be achieved by co-administration of hydroxychloroquine (HCQ) and tamoxifen (TAM) [148]. TAM is a commonly used estrogen blocker, in breast cancer but many patients become unresponsive to or develop resistance to it [149]. Oral administration of low-dose HCQ along with TAM and/or Falsodexin in female athymic mice, which bearing TAM-resistant MCF7-RR and antiestrogen (ICI)-resistant/TAM cross-resistant LCC9 ER+ breast cancer cells in mammary fat pads, restored antiestrogen sensitivity. In metastatic colorectal cancer, SET protein deregulation is implicated in promoting cell growth and colonosphere formation and inhibiting antitumor effects of protein phosphotase 2A (PP2A) [147]. Furthermore, SET de-sensitizes colorectal cancer cells to oxaliplatin, is overexpressed in over $24 \%$ of patients, and is associated with shorter overall and progressionfree survival. FTY720, an activator of PP2A, restored sensitivity to oxaliplatin when used as a combinatorial treatment [147].

\section{Nanotechnology for Combination Therapy}

Application of nanotechnology is becoming increasingly prevalent in drug delivery for cancer therapy, particularly in combinatorial treatments [11]. Nanocarriers help prevent drug degradation by evading the reticuloendothelial system (RES) and increase the bioavailability of 
the therapeutic agents at the target site [150-152]. In turn, adverse systemic side effects often decrease, while efficacy of the drug is enhanced. The most important advantage of drug delivery systems, which cannot be easily replaced by other means, is co-delivery of multiple therapeutic agents on the same platform in a timely and spatially controlled manner, resulting in normalized pharmacokinetics and pharmacodynamics of multiple therapeutic agents [29].

\subsection{Optimal design of delivery systems for combination therapy}

Nanomaterials have shown to be extremely useful for co-delivery of multiple chemotherapeutic agents, and dynamic materials can achieve maximum therapeutic effects through multi-modal cancer treatments $[11,12$, ]. Developing a suitable carrier for chemically dissimilar agents is often the first step toward an effective delivery, and drug loading is highly dependent upon the size and structure of the delivery method [153]. Liposomes, double emulsion surfactants, micelles, self-assembled polymers, and hydrogels as shown in Figure 4 are some examples of micro- and

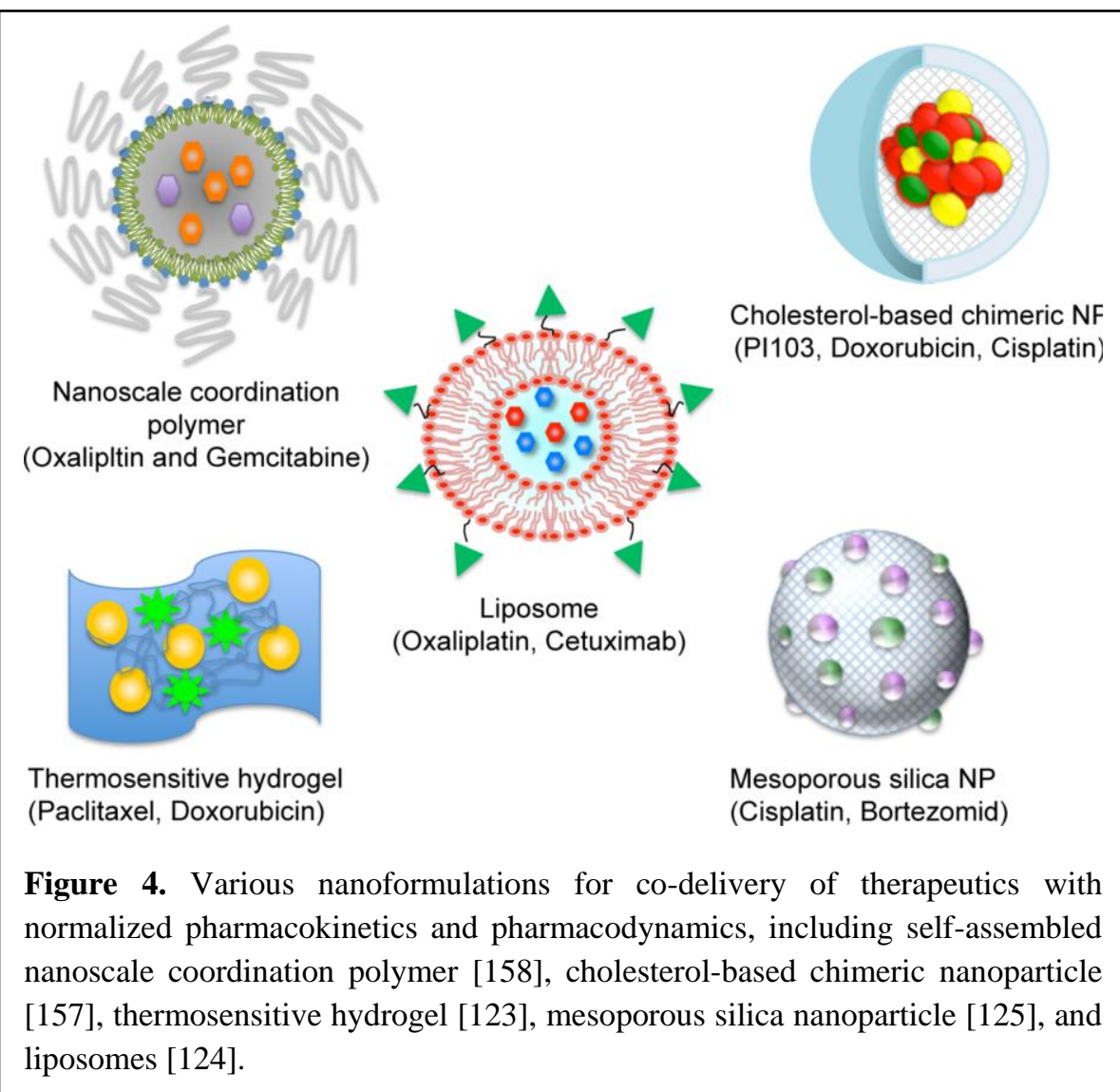

nano-sized delivery systems commonly used for co-delivery of therapeutic agents [154]. Drugs may be covalently conjugated to polymers or peptides, loaded into nanoparticles via nanoprecipitation, emulsion, solvent evaporation, or soft lithography [155]. Biodegradation of a carrier and diffusion are two processes directing 
drug release from a nanocarrier, with the release rate depending upon drug desorption and diffusion through the NP matrix/matrix erosion [156]. Therefore, selection of specific materials can determine key drug delivery parameters such as ratios and release times. A cholesterolbased, biodegradable, non-toxic chimeric nanoparticle was recently designed to co-deliver DOX, PI3K inhibitor PI103, and cisplatin in a controlled ratio through chemical conjugation [157]. The nanoparticles demonstrated enhanced in vitro toxicity compared to the co-administration of the free drugs in HL60, MCF7, and MDA-MB-231 cancer cells. A nanoscale coordination polymer, constructed through self-assembly processes of polydentate bridging ligands and metal ions/clusters, was recently used as a novel carrier to co-deliver oxaliplatin (30 wt. \%) and gemcitabine (12 wt. \%) [158]. The combination therapy demonstrated enhanced antitumor efficacy in human pancreatic ductal adenocarcinoma xenograft mouse models, with the NPs exhibiting biodegradability, low toxicity, and long blood circulation half-lives. Incorporation into a macromolecular platform often results in prolonged circulation of multiple drugs in nanocarriers and allows for synergistic dosing by extending the therapeutic window [159].

Specific and effective combination therapies often necessitate triggered drug release in response to external or internal stimuli [160-165]. Ideal NPs with high selectivity toward cancerous cells, accompanied by targeted drug release in response to distinctive characteristics such as slightly acidic $\mathrm{pH}$ in the tumor microenvironment or overexpressed receptors, can decrease the minimally required dosage of therapeutics. For example, "nano-cocoons" were made from a single strand of self-assembled DNA with an acid-cleavable core containing DOX- and DNase [166]. The cocoons targeted cells overexpressing folic acid receptors, and DOX was selectively released from the DNA cocoon upon exposure to endosomal $\mathrm{pH}$. Liposomes holding an ATPresponsive, DOX-containing scaffold were paired with complementary liposomes encasing ATP to initiate drug release within endosomal $\mathrm{pH}$ [167]. The specific release of DOX resulted in enhanced antitumor efficacy over that of the free drug in MCF-7 cancer xenograft nude mice. The same group also developed spherical NPs that encapsulated a complex of DOX, ATPresponsive DNA, and protamine for selective release of DOX [168]. The resulting NPs released DOX intracellularly in response to high ATP and cytotoxicity against MDA-MB-231 cells and xenograft tumors. 
Overexpressed proteins in the tumor microenvironment can aid in selective therapeutic release. For example, viral capsids were genetically engineered with peptides to be cleaved by matrixmetalloproteinases [27]. The nanonodes were designed for the virus to be activated only in the presence of two different proteases, therefore demonstrate high control over release under certain conditions, and can be fabricated to target proteases overexpressed in tumor microenvironment. Likewise, overexpression of matrix-metalloproteinase 9 in lung tumors was utilized to release cisplatin and bortezomid from avidin-capped mesoporous silica NPs [169]. The avidin caps were cleaved only by these proteinases, therefore controlled release and synergistic therapeutic effects were observed in vitro and ex vivo. To treat EGFR-expressing wild-type KRAS metastatic colorectal cancer, Oxaliplatin was incorporated into liposomes conjugated with cetuximab on the surface [170]. Liposomes with cetuximab linked to the surface demonstrated up to a 3-fold higher level of intracellular drug delivery in cells over-expressing EGFR.

Multiple agents may be released concomitantly or in sequence, depending upon the desirable kinetics and timing of drugs, and the formulation within the nanocarrier [171-173]. For example, Epigallocatechin gallate (EGCG) and Paclitaxel (PTX) were co-formulated within a targeted core shell PLGA-casein nanoparticle to be released in sequence to allow for NF- $\kappa \mathrm{B}$ downregulation and enhanced activity of PTX [174]. Certain NF- $\kappa$ B-inducible genes have been shown to protect MDA-MB-231 human breast cancer cells against Paclitaxel [175], and EGCG has demonstrated down-regulation of NF- $\kappa \mathrm{B}$ amongst other key regulatory proteins [176]. The nanoparticles re-sensitized PTX-resistant human breast cancer cells to PTX, afforded substantial cytotoxicity, and repressed expression of P-gp [174]. The nanoparticles also inhibited NF- $\kappa \mathrm{B}$ activation and down-regulated several significant genes associated with angiogenesis, tumor metastasis and survival.

Utilization of a nanoparticle carrier can effectively transport two therapeutics that have different chemical properties, such as hydrophobicity vs hydrophilicity $[177,178]$. For example, a drugcontaining monomer, $g$-camptothecin-glutamate $N$-carboxyanhydride (Glu(CPT)-NCA), was directly polymerized on to a poly(ethylene glycol) (PEG)-based chain to form monodispersed nanoparticles (NPs) through self-assembly, and doxorubicin (DOX) was subsequently loaded in [179]. An in- vivo study showed improved antitumor activity over free drugs via enhanced accumulation of the nanocarriers in tumor site. A thermosensitive, multi-compartment, and 
injectable hydrogel was engineered using assembly of PEGylated fluorocarbon and PEGylated hydrocarbon nanoparticles [180]. The injectable material incorporated PTX and DOX separately and released simulatenously to achieve a synergistic effect in vitro and in vivo in human breast carcinoma cells and xenograft mouse models, respectively.

Nanomaterials are highly versatile and adaptable, making for excellent platforms to achieve codelivery of multiple therapeutics. Various formulations such as liposomes, polymer microcapsules, microspheres, and polymer conjugates are in clinical development or are even FDA-approved [153]. As with any novel therapy, factors such as production cost, scalability, safety, and complexity of nano-formulations must be considered and weighed against the potential benefits. In certain cases co-formulation within a single platform may not be feasible or clinically beneficial, so one alternative may be co-administration of nanomedicines.

\subsection{Combined gene and chemotherapy}

Gene therapy helps eliminate cancer by delivering nucleic acids to express pro-apoptotic proteins or substitute mutated genes, down-regulate or silence oncogenic pathways, produce anti-cancer cytokines, and activate the immune system against cancer (e.g., engineered T cells with chimeric antigen receptors [CARs]) [181, 182]. One approach to treating cancer using combined gene and chemotherapy is to administer gene therapy against a drug resistance pathway [183]. One of the challenges associated with this approach is the co-delivery of nucleic acids and small molecule drugs because of their significantly different physico-chemical properties [184]. Attempts to develop nanocarriers for co-delivery of small interfering RNA (siRNA) and small molecule drugs continue to grow, particularly in recent years [185]. Combined gene and chemotherapy requires nanocarriers to be inert in nature, non-immunogenic, non-toxic, capable of effectively condensing and immobilizing nucleic acids, and encapsulating small molecules [186].

Drug resistance can occur through various means, which is why combating this process requires a multi-faceted approach such as combined gene and chemotherapy [187]. For example, drug resistance associated with P-glycoprotein (P-gp) drug efflux pump that is activated primarily by the MDR-1 gene can be reversed by RNA interference (RNAi) against P-gp [188]. Although Pgp-associated drug resistance may be overcome solely by endocytic delivery using nanomaterials 
[189], siRNA against MDR-1 in combination with therapeutics shows enhanced efficacy over nano-formulated drugs alone [190]. Multifunctional mesoporous silica NPs loaded with DOX and siRNA against P-gp drug efflux pump demonstrated enhanced capability to overcome drug resistance in breast cancer models in vitro and in vivo. In another recent study, assembly of a nanocomplex, consisting of MDR-1 siRNA and a dextran-based polymer, was loaded with DOX and showed a significant increase in DOX uptake by MDR cells and reversed drug resistance in osteosarcoma [191]. For combating drug resistance irrelevant to efflux pumps, RNAi against cell survival pathways, transcription factors, and anti-apoptotic proteins can be utilized. For example, myeloid cell leukemia-1 (Mcl-1) and B-cell lymphoma-2 (Bcl-2) proteins, which are often overexpressed in many cancers, interfere with apoptosis and induce drug resistance, making them promising targets of RNAi. TP53, the p53 tumor suppressor gene, is commonly mutated in various cancers, and restoration of its function promotes antitumor effects [192]. miR-34a, a p53regulated miRNA, can stimulate the p53 pathway and reestablish the downstream effects [193]. In a murine mouse model of lung cancer, a lipid/polymer nanoparticle delivering miR-34a slowed tumor growth [194]. Additionally, a KRAS-targeting siRNA was shown to decelerate tumor growth as well. Formulated into the same nanoparticle, the combination of both the miRNA and siKRAS caused the regression of tumors and a 50\% reduction of size. Furthermore, when combined with traditional treatment of cisplatin, the NPs extended life by an additional $25 \%$. Co-delivery of a chemotherapeutic agent along with siRNA against one or more of the aforementioned targets could synergistically induce the apoptosis of cancer cells.

\subsection{Physically enhanced chemotherapy}

Multi-modal treatments have the advantage of eradicating cancer through processes which are infallible and inescapable. Physically activated modalities (e.g., photothermal, photodynamic, radio-, and magnetically assisted therapies) also offer a synergistic approach to eradicating cancer by generating a broad range of various therapeutic effects, upon receipt of an external trigger (e.g., laser, NIR, X-ray, and magnetic field). Drugs or nucleic acids alone are incapable of producing effects which cancer cells do not develop resistance via mutations such as tumor ablation of (Figure 5). Nanocarriers used in physically enhanced chemotherapy are summarized in Table 2. 


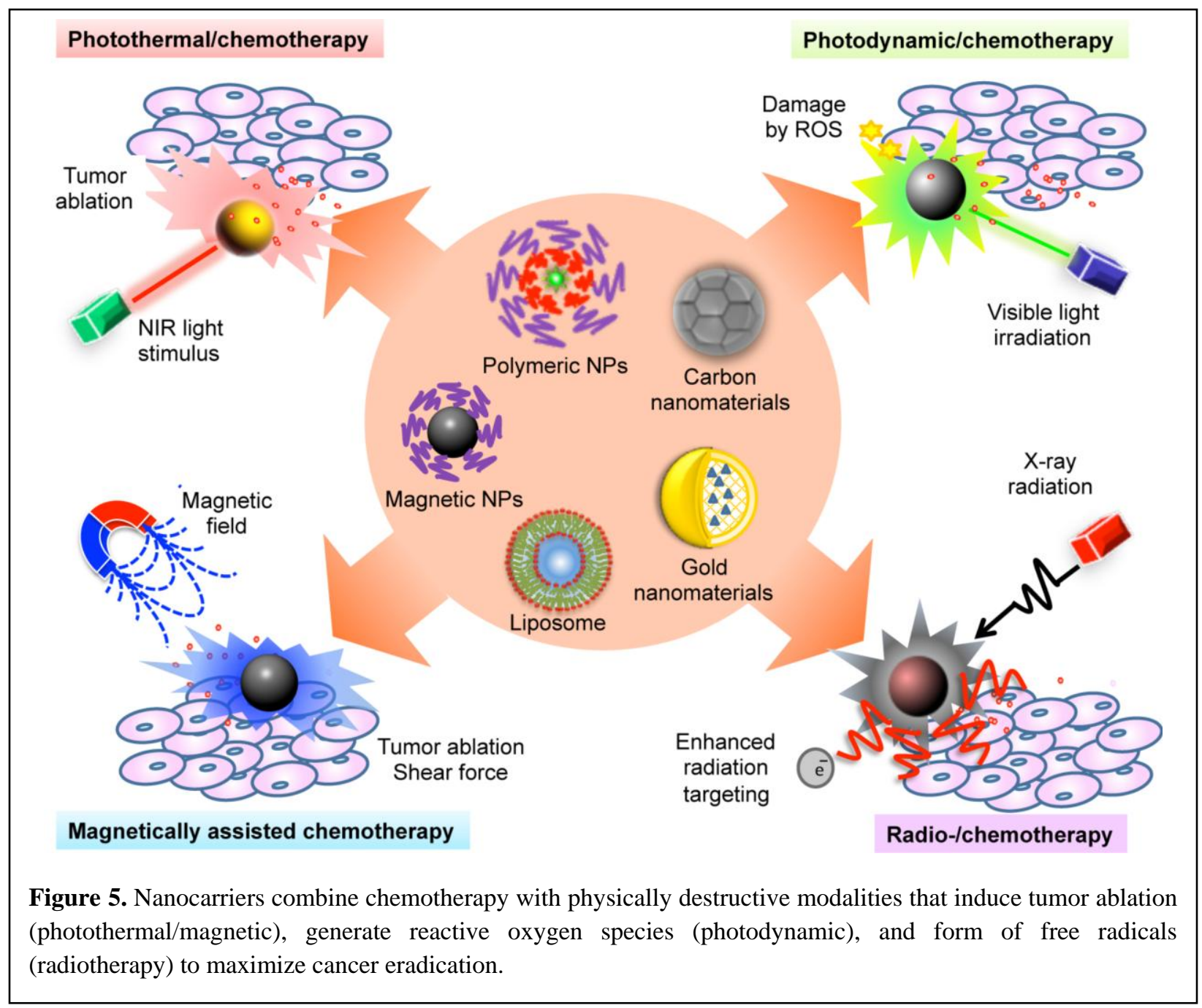

\subsubsection{Combined photothermal and chemotherapy}

Inducing hyperthermia in the body tissue has been used to kill cancer cells effectively in a target area [195]. However, traditional hyperthermia is usually invasive, non-uniform, and desired therapeutic efficacy without non-specific cell damage requires sophisticated temperature control [196]. Various nanomaterials with a high-absorption cross-section for converting an external energy source (e.g., magnetic field, light, and ultrasound) into heat have been developed for minimally invasive and uniform hyperthermia [197-203]. Particularly, gold and carbon nanomaterials whose hyperthermal effects are triggered upon irradiation by noninvasive, deeppenetrating near-infrared light (NIR) have been widely explored as efficient agents for photothermal therapy [204] [34-36]. Drugs bound to the large surface area or encapsulated in the interior of nanomaterials [205,206] can be released in a controllable manner [33] when 


\begin{tabular}{|c|c|c|c|}
\hline Nanomaterial & Modes of therapy & Target & Ref. \\
\hline $\begin{array}{l}\text { Mesoporous silica gold } \\
\text { nanoshell }\end{array}$ & Photothermal, Docetaxel & $\begin{array}{l}\text { Human liver carcinoma (in vitro/in } \\
\text { vivo) }\end{array}$ & 215 \\
\hline Hollow gold PEGylated NPs & $\begin{array}{l}\text { Photothermal, Doxorubicin, NIR- } \\
\text { triggered release }\end{array}$ & $\begin{array}{l}\text { Human breast adenocarcinoma (in } \\
\text { vitro/in vivo) }\end{array}$ & $\begin{array}{l}218, \\
219\end{array}$ \\
\hline $\begin{array}{l}\text { Hollow gold NPs fused to } \\
\text { liposome }\end{array}$ & NIR-triggered release of Doxorubicin & $\begin{array}{l}\text { Human hepatocellular carcinoma } \\
\text { (in vitro/in vivo }\end{array}$ & 220 \\
\hline $\begin{array}{l}\text { Mesoporous magnetic gold } \\
\text { nanoclusters }\end{array}$ & $\begin{array}{l}\text { Photothermal, Doxorubicin, magnetic } \\
\text { triggered release }\end{array}$ & 4T1 breast cancer (in vitro/in vivo) & 221 \\
\hline $\begin{array}{l}\text { Gold nanocages coated } \\
\text { with magnetic NPs }\end{array}$ & $\begin{array}{l}\text { Photothermal, Doxorubicin, magnetic } \\
\text { triggered release, imaging }\end{array}$ & Human breast cancer (in vitro) & 223 \\
\hline Mesoporous carbon NPs & $\begin{array}{l}\text { Photothermal, Doxorubicin, folic acid } \\
\text { conjugated }\end{array}$ & Human cervical carcinoma (in vitro) & 226 \\
\hline $\begin{array}{l}\text { Single-walled carbon } \\
\text { nanotube }\end{array}$ & $\begin{array}{l}\text { Photothermal, Docetaxel, RGD-peptide } \\
\text { conjugated }\end{array}$ & $\begin{array}{l}\text { Human prostate cancer (in vitro) } \\
\text { s180 (in vivo) }\end{array}$ & 229 \\
\hline $\begin{array}{l}\text { PEGylated nanographene } \\
\text { oxide }\end{array}$ & Photothermal, Doxorubicin & $\begin{array}{l}\text { Murine mammary carcinoma (in } \\
\text { vitro/ in vivo }\end{array}$ & 230 \\
\hline Bovine serum albumin NPs & $\begin{array}{l}\text { Photodynamic, Doxorubicin, } \\
\text { hematoporphyrin conjugated }\end{array}$ & $\begin{array}{l}\text { Human hepatocellular carcinoma } \\
\text { (in vitro/in vivo) }\end{array}$ & 234 \\
\hline Polymeric NPs & $\begin{array}{l}\text { Photodynamic, Docetaxel, zinc } \\
\text { phthalocyanine loaded }\end{array}$ & $\begin{array}{l}\text { orthotopic amelanotic melanoma } \\
\text { (in vitro/in vivo) }\end{array}$ & 235 \\
\hline Polymeric micelles & Photodynamic, Paclitaxel, chlorin core & Human breast cancer (in vivo) & 238 \\
\hline Polymeric-pyrolipid NPs & Photodynamic, cisplatin & $\begin{array}{l}\text { Head and neck cancer (in vitro/in } \\
\text { vivo) }\end{array}$ & 240 \\
\hline $\begin{array}{l}\text { Polyethyleneimine- } \\
\text { conjugated fullerene }\end{array}$ & $\begin{array}{l}\text { Photodynamic, Doxorubicin, } \mathrm{pH}- \\
\text { triggered release }\end{array}$ & Murine melanoma (in vitro/in vivo) & 241 \\
\hline Fullerene-loaded micelles & Photodynamic, Docetaxel, & $\begin{array}{l}\text { Human cervical cancer (in vitro/in } \\
\text { vivo) }\end{array}$ & 242 \\
\hline Gold NPs & Radiotherapy, cisplatin & Glioblastoma (in vitro) & 243 \\
\hline Copper sulfide NPs & Radiotherapy, photothermal & $\begin{array}{l}\text { Murine mammary carcinoma (in } \\
\text { vitro/in vivo) }\end{array}$ & 198 \\
\hline Hollow gold NPs & $\begin{array}{l}\text { Radiotherapy, photothermal, } \\
\text { Doxorubicin, CT imaging }\end{array}$ & $\begin{array}{l}\text { Human lung carcinoma (in vitro/in } \\
\text { vivo) }\end{array}$ & 199 \\
\hline $\begin{array}{l}\text { Gold/graphene oxide core- } \\
\text { shell NPs }\end{array}$ & $\begin{array}{l}\text { Photothermal, photodynamic, Raman } \\
\text { bioimaging }\end{array}$ & Human cervical cancer (in vitro) & 200 \\
\hline Mesoporous carbon NP & $\begin{array}{l}\text { Photothermal, doxorubicin, glutathione- } \\
\text { triggered release }\end{array}$ & $\begin{array}{l}\text { Human breast adenocarcinoma (in } \\
\text { vitro) }\end{array}$ & 201 \\
\hline $\begin{array}{l}\text { Mesoporous silica-CuS- } \\
\text { coated NPs }\end{array}$ & Photothermal, doxorubicin & $\begin{array}{l}\text { Human hepatocellular carcinoma } \\
\text { (in vitro) }\end{array}$ & 202 \\
\hline Polypyrrole NPs & $\begin{array}{l}\text { Photothermal, photodynamic, chlorin- } \\
\text { conjugated }\end{array}$ & $\begin{array}{l}\text { Murine mammary carcinoma (in } \\
\text { vitro/in vivo) }\end{array}$ & 203 \\
\hline $\begin{array}{l}\text { Liposomes with magnetic } \\
\text { core NPs }\end{array}$ & Photodynamic, magnetic hyperthermia & $\begin{array}{l}\text { Human ovarian cancer (in vitro) } \\
\text { epidermoid carcinoma (in vivo) }\end{array}$ & 245 \\
\hline $\begin{array}{l}\text { Superparamagnetic iron } \\
\text { oxide NPs }\end{array}$ & $\begin{array}{l}\text { Magnetic field-induced shear force, } \\
\text { conjugated LAMP-1 antibodies }\end{array}$ & $\begin{array}{l}\text { Rat insulinoma, human pancreatic } \\
\text { cells (in vitro) }\end{array}$ & 246 \\
\hline
\end{tabular}

hyperthermia is induced. Moreover, nanoscale carriers can cross a tumor endothelium and 
passively accumulate in tumors owing to the leaky blood vessels and poor lymphatic drainage [207, 208]. Utilization of nanomaterials that allow the combination of photothermal and chemotherapy has proven to be an effective approach for cancer treatment [32].

Gold nanomaterials, such as gold nanoshells (AuNSs), gold nanorods (AuNRs), and gold nanocages (AuNCs), exhibit unique size- and shape-dependent optical and photothermal properties due to localized surface plasmon resonance (SPR) at the NIR region [209-212-], with high biocompatibility and facile surface functionalization [213, 214]. Combined photothermal and chemotherapy via ablation of hepatocellular carcinomas both in vivo and in vitro was explored using gold nanoshells (AuNSs) [215, 216] consisting of a mesoporous silica nanorattle core and a thin outer gold shell [215]. Over $60 \%$ of docetaxel (DTX) encapsulated in PEGylated AuNS on silica nanorattle spheres (pGSNs) was released within 1 week. A synergistic killing of HepG2 cells both in vivo and in vitro was significantly improved compared to chemotherapy or photothermal therapy alone. In addition, transferin-conjugated pGSNs demonstrated effective targeting. DOX-loaded PEG-PLGA nanomicelles with thin gold shell coating (DOX/PEGPLGA@AuNSs nanocomposite,) [216] with SPR absorption at $790 \mathrm{~nm}$, increased the intratumoral temperature to $50-70{ }^{\circ} \mathrm{C}$ upon NIR laser irradiation, and rapidly released DOX, leading to complete tumor eradication without weight loss or tumor recurrence. Biocompatible PLGA-based microspheres containing paclitaxel (PTX) and hollow gold nanoparticles (HAuNPs) rapidly released PTX at elevated local temperatures upon NIR irradiation [217] and demonstrated higher anticancer activity in vitro and in vivo than PTX/PLGA/HAuNPs microspheres alone (no NIR-irradiation) or PLGA/HAuNPs microspheres (no PTX) with NIR irradiation. DOX-loaded, PEG-conjugated hollow gold nanoparticles (DOX/PEG/HAuNPs) demonstrated NIR-triggered, pH-dependent DOX release led to greater antitumor activity and decreased systemic toxicity than free DOX or liposomal DOX [218, 219]. DOX-containing liposomes tethered with hydrophobically modified HAuNPs on the surface significantly increased DOX release via liposome phase transition and increased permeability only upon NIR irradiation [220], resulting in significantly increased anti-tumor activity than liposomes alone, DOX alone, or DOX-free liposomes alone, both in vitro and in vivo. Mesoporous silica-coated gold nanorods loaded with DOX (pGNRs@mSiO $2-\mathrm{DOX}$ ) led to significant damage in breast cancer cells in vitro and significantly suppressed tumor growth in mice upon NIR irradiation 
[221]. Gold nanocages (AuNCs) with hollow interiors and porous walls were further functionalized with calcium phosphate $(\mathrm{CaP})$-coated magnetic $\mathrm{NPs}\left(\mathrm{Fe}_{3} \mathrm{O}_{4} @ \mathrm{CaP}\right)$ as pore blockers preventing premature release of the entrapped drugs before reaching mildly acidic endosomes [222]. Decreased viscosity of surrounding fluid after NIR-triggered heating accelerated DOX release from the AuNCs, and revealed higher anticancer efficacy than the sum of cytotoxic effects of DOX-loaded AuNCs alone and DOX-free AuNCs with NIR-irradiation. The magnetic NPs bound to AuNCs showed the potential for magnetic resonance imaging (MRI) and target-specific drug delivery.

Carbon nanomaterials, particularly nanotubes (CNTs) and graphenes, are NIR-absorbing photothermal materials that can be used for combined photothermal and chemotherapy [36,223, 224]. The ultrahigh surface area of carbon nanomaterials offers efficient molecular loading via covalent conjugation [225] and $\pi-\pi$ stacking [226]. Carbon nanomaterials coated with biocompatible materials have been found to be cleared from body after systemic administration without noticeable toxicity in animals [227]. Mesoporous carbon NPs functionalized with polyethylenimine (PEI) and folic acid (FA) (FA/PEI/MCNPs) [228] showed strong NIR absorption and high photothermal conversion efficiency due to the graphitic structure of MCNPs. Compared with chemotherapy or photothermal therapy alone, DOX-loaded FA/PEI/MCNPs demonstrated synergistic therapeutic efficacy in FAR-overexpressing HeLa cells. RGD peptidelinked, DTX-conjugated single-walled CNTs (RGD/DTX/SWNT) [229] demonstrated higher tumor-suppressing efficacy upon NIR irradiation than DTX both in PC3 cell line and a murine S180 cancer model. Combined photothermal and chemotherapy using DOX-loaded PEGylated nanographene oxide (NGO-PEG-DOX) [230] demonstrated synergistically enhanced therapeutic effects with low toxicity in main organs. A targeted, combined photothermal and chemotherapy was also demonstrated in vitro using polyvinylpyrrolidone (PVP)-functionalized, folic acid (FA) conjugated NGO (FA-NGO-PVP) [231].

\subsubsection{Combined photodynamic and chemotherapy}

Photodynamic therapy is a non-invasive, emerging clinical modality for cancer therapy with reduced side effects [232]. Upon activation by the proper wavelength of light, the photosensitizers generate highly reactive singlet oxygen by transferring energy to molecular 
oxygen, causing cell death and tissue destruction [233]. Combination with chemotherapy can maximize the therapeutic effect of photodynamic therapy, and there has been great effort to develop various nanomaterials for co-delivery of photosensitizers and anticancer drugs.

Hematoporphyrin (HP)-modified, bovine serum albumin (BSA) NPs (HP-NPs) loaded with DOX were developed for combination chemo-photodynamic therapy to treat liver cancer [234]. HP was utilized as a ligand for low density lipoprotein (LDL) receptors on the hepatoma cells and for its photosensitizing capabilities. Anticancer activity of HP-NPs against human hepatocellular carcinoma HepG2 cells was significantly increased in vitro and in vivo, according to the irradiation time and number of PDT sessions. DTX- and zinc-phthalocyanine (ZnPc)loaded "core-shell" NPs that were made of poly( $\varepsilon$-caprolactone) (PCL) and PEG block copolymers [235] showed sustained release of DTX, without ZnPc release, and singlet oxygen generation only upon irradiation at $610 \mathrm{~nm}$. The ZnPc/DTX-loaded NPs exhibited high stability in the presence of serum proteins and a superior anticancer activity in an animal model of orthotopic amelanotic melanoma, as compared to DTX-loaded NPs. In another example, supramolecular self-assembled NPs were synthesized by host-guest interactions for chemophotodynamic therapy against cisplatin-resistant cancer cells [236]. Modified porphyrin served as a guest molecule within the bridged $\beta$-cyclodextrin dimer host bridged by a platinum(IV) prodrug. Cellular uptake through endocytosis prevented cisplatin from being recognized by drug efflux pumps on the cell membrane, and cellular ROS were generated upon visible light irradiation, leading to synergistic anticancer activity. Photosensitizer tetrakis(4carboxyphenyl)porphyrin conjugated with methoxy PEG (mPEG-por) was self-assembled into NPs incorporating DOX via $\pi-\pi$ stacking interactions [237]. The DOX-loaded mPEG-por NPs exhibited efficient anticancer activity both in vitro and in vivo upon laser irradiation. PTX was loaded into micellar carriers consisting of amphiphilic 4-armed, star-shaped diblock copolymers of methoxy PEG and PCL with a chlorin-containing core [238]. The resulting chlorin-core micelles rapidly released PTX under an acidic condition and synergistically improved the cytotoxicity against MCF-7 cells upon irradiation. Similarly, chlorin-core micelles encapsulating SN-38 anticancer drug showed increased tumor accumulation via prolonged residence time in plasma, as compared to free camptothecin anticancer drug, and synergistically inhibited tumor growth in a colon cancer xenograft model after light irradiation [239]. After 3 treatments with the 
micelles tumor regression was observed along with decreased microvessel density and cell proliferation. Nanoscale coordination polymer (NCP)-based core-shell NPs highly loaded with cisplatin and photosensitizer pyrolipid (NCP@pyrolipid) [240] released payloads upon laser irradiation, prolonged blood circulation times, and showed increased accumulation in tumor. Compared to monotherapy, NCP@pyrolipid exhibited superior efficacy in a cisplatin-resistant human head and neck cancer SQ20B xenograft murine model.

DOX was conjugated with PEI-derivatized fullerene via a $\mathrm{pH}$-sensitive hydrazone linkage, and resulting $\mathrm{C}_{60}$-PEI-DOX [241] exhibited selective accumulation of DOX in the tumorand a synergistic antitumor efficacy with photodynamic therapy in an animal tumor model after intravenous injection. Diadduct malonic acid-fullerene (DMA-C 60 )- and DTX-encapsulating mPEG-PCL micelles (DMA-C 60 /DTX) [242] showed sustained release of the payloads and subsequently generated ROS in cancer cells upon irradiation with $532 \mathrm{~nm}$ light. Cells treated with DMA-C 60 /DTX and light irradiation underwent apoptosis at a greater magnitude than those treated with DTX micelles, demonstrating the photodynamically-augmented cytotoxicity of DMA-C $_{60}$. Intravenous injection of DMA-C 60 DTX with irradiation exhibited higher tumor suppression efficiency than DTX micelles in murine sarcoma tumor-bearing mice.

\subsubsection{Further modes of physical ablation}

Radiotherapy utilizing high-energy radiation is commonly a part of cancer therapy in the clinic. Radiation therapy is quite successful at eradicating cancer cells, but with adverse side effects ranging from damaged heart and lung tissue to infertility and even in some cases, development of a secondary cancer $[198,199]$. Furthermore, the cells in solid tumors are much more resistant to the treatment due to the hypoxic nature of the intratumor environment. One approach to circumvent this significant challenge in radiotherapy is the development of nanocarriers to combine chemotherapeutics with radiosensitizers to synergistically increase the effectiveness of radiation therapy. Certain nanomaterials can be utilized as adjuvant radiosensitizers in combination with other therapies such as tumor ablation. For example, HAuNPs capable of generating SPR effects for photothermal ablation can be easily loaded with chemotherapeutics while the gold particles serve as radiosensitizers. For example, Cisplatin-tethered AuNPs (PtAuNPs) were internalized into live patient-derived glioblastoma multiforme (GBM) brain tumor 
cells and induced caspase-mediated cell apoptosis in vitro [243]. Both Au and Pt of Cisplatin, high atomic number radiosensitizers, emit ionizing photoelectrons and Auger electrons upon radiation. These high-energy electrons hydrolyzed intracellular water and led to the production of cytotoxic ROS for significantly inhibited the growth rate of cancer cells. The synergistic therapeutic effect reduced the visible cell population by one hundred thousand fold compared to untreated cells, and there was no further renewal of the cancerous cell population.

Magnetic nanomaterials can be employed in multi-modal treatments for tumor ablation, imaging, and controlled release [244]. Iron oxide NPs and a hydrophobic photosensitizer m-THCP, commercially used and known as Foscan, were loaded into the lipid bilayer of liposomes to pair magnetically induced hyperthermia and photodynamic therapy for tumor ablation [245]. The pairing led to complete tumor eradication in vivo but the individual treatments only inhibited tumor growth, indicating the strong synergistic effect. In another approach, superparamagnetic iron oxide NPs (SPIONs) conjugated with lysosomal protein LAMP1-targeting antibodies induced apoptosis upon rotation activation by exposure to a magnetic field [246]. The NPs accumulated along the membrane in lysosomes due to the conjugated antibodies in rat

insulinoma tumor cells and human pancreatic beta cells. The increase in torque resulted in tearing of the membrane, followed by amplified expression of early and late apoptotic markers, and impaired cell growth. Since rotation of the magnetic NPs is controlled to affect only the tumor cells entered, this method may serve to be superior to previous attempts that use magnetic fields to create heat for tumor ablation, which can cause inflammation to healthy surrounding tissue.

\section{Concluding Remarks}

Advances in understanding underlying molecular mechanisms of cancer biology have guided design of new therapeutic agents. However, monotherapies using a single therapeutic modality rarely catch up to the versatile nature of cancer and the rampant formation of drug resistance. A key dilemma in using one drug for cancer therapy incorporating two desirable yet contradicting goals: acting on a specific target pathway and tackling multiple pathogenic pathways. Therefore, combinatorial therapies using multiple therapeutic agents together for generating synergistic effects is a logical and promising approach to combat cancer. Combinatorial approaches 
formulate the most effective and safe therapy in response to the dynamic nature of and drug resistances found in cancer. Despite the great promise of combinatorial therapies, it is indispensable to ensure that treatments are synergistic and complementary. In depth analysis of cancer pathways affected, feedback loops, alternative mechanisms, and genetic profiles must all be considered prior to combination of therapeutic agents. A simple combination of drugs based on their capacity for cell death will only increase systemic toxicity and may incur new resistances as cancer cells evolve over time. Employing nanotechnology in co-delivery of multiple therapeutic agents offers significant advantages, including normalized pharmacokinetics and pharmacodynamics, sustained bioavailability, targeted accumulation, and controlled and ordered drug release. Nanoplatforms hold functionalities that drugs alone do not possess, such as specific binding to target cells, generation of imaging signals, and responsiveness to external triggers. Nanomaterials' potential adverse effects need to be also considered when designing multi-modal therapies. Certain nanomaterials have been associated with oxidative stress, undesirable inflammatory responses, and genotoxicity [227, 247]. Critical evaluation is necessary of whether benefit outweighs the adverse effect and whether it is to a significant

degree. In addition, the "combo" nanomedicine should not require significantly higher level of complexity and difficulty in manufacturing, characterization, and assessment. Taking therapeutics from bench to bedside is extremely challenging, and once again, the cost vs. benefit must be judiciously mapped out. The "combo" nanomedicine enables novel and new classes of multi-dimensional therapies in combination of chemotherapy, gene therapy, photothermal therapy, photodynamic therapy, and immunotherapy, which may ultimately serve to be a solution to overcome various resistances. It is of the utmost importance that collaborative efforts are taken in developing such therapies by combining the knowledge and expertise of cancer biology, nanotechnology, bioinformatics, and pharmaceutical development fields.

\section{Acknowledgement}

This study was financially supported by the National Science Foundation (DMR-0956091), Gabrielle's Angel Foundation for Cancer Research (Award 56), and University of California Cancer Research Coordinating Committee Research Award (UCRCC-103955) 


\section{References}

[1] Uzgare, A. R., Kaplan, P. J., \& Greenberg, N. M. (2003). Differential expression and/or activation of P38MAPK, erk1/2, and jnk during the initiation and progression of prostate cancer. The Prostate, 55(2), 128-139.

[2] Krishnan, V., \& Rajasekaran, A. K. (2014). Clinical nanomedicine: a solution to the chemotherapy conundrum in pediatric leukemia therapy. Clinical Pharmacology \& Therapeutics, 95(2), 168-178.

[3] Liang, X. J., Chen, C., Zhao, Y., \& Wang, P. C. (2010). Circumventing tumor resistance to chemotherapy by nanotechnology. In Multi-Drug Resistance in Cancer (pp. 467-488). Humana Press.

[4] Morton, S. W., Lee, M. J., Deng, Z. J., Dreaden, E. C., Siouve, E., Shopsowitz, K. E., Shah, N. J., Yaffe, M.B., \& Hammond, P. T. (2014). A nanoparticle-based combination chemotherapy delivery system for enhanced tumor killing by dynamic rewiring of signaling pathways. Science Signaling, 7(325), ra44.

[5] Burrell, R. A., McGranahan, N., Bartek, J., \& Swanton, C. (2013). The causes and consequences of genetic heterogeneity in cancer evolution. Nature,501(7467), 338-345.

[6] Marusyk, A., Tabassum, D. P., Altrock, P. M., Almendro, V., Michor, F., \& Polyak, K. (2014). Non-cell-autonomous driving of tumour growth supports sub-clonal heterogeneity. Nature, 514(7520), 54-58.

[7] Turner, N. C., \& Reis-Filho, J. S. (2012). Genetic heterogeneity and cancer drug resistance. The Lancet Oncology, 13(4), e178-e185.

[8] Lee, H. J., Zhuang, G., Cao, Y., Du, P., Kim, H. J., \& Settleman, J. (2014). Drug resistance via feedback activation of Stat3 in oncogene-addicted cancer cells. Cancer Cell, 26(2), 207-221.

[9] Griner, L. A. M., Guha, R., Shinn, P., Young, R. M., Keller, J. M., Liu, D., Goldlust, I. S., Yasgar, A., McKnight, C., Boxer, M. B., Duveau, D. Y., Jiang, J. K., Michael, S., Mierzwa, T., Huang, W., Walsh, M. J., Mott, B. T., Patel, P., Leister, W., Maloney, D. J., Leclair, C. A., Rai, G., Jadhav A., Peyser, B. D., Austin, C. P., Martin, S. E., Simeonov, A., Ferrer, M., Staudt, L. M., \& Thomas, C. J. (2014). High-throughput combinatorial screening identifies drugs that cooperate with ibrutinib to kill activated B-cell-like diffuse large B-cell lymphoma cells. Proceedings of the National Academy of Sciences of 
the United States of America, 111(6), 2349-2354.

[10] Berns, K., \& Bernards, R. (2012). Understanding resistance to targeted cancer drugs through loss of function genetic screens. Drug Resistance Updates, 15(5), 268-275.

[11] Hu, C. M. J., \& Zhang, L. (2012). Nanoparticle-based combination therapy toward overcoming drug resistance in cancer. Biochemical Pharmacology,83(8), 1104-1111.

[12] Gao, Z., Zhang, L., \& Sun, Y. (2012). Nanotechnology applied to overcome tumor drug resistance. Journal of Controlled Release, 162(1), 45-55.

[13] Mei, L., Zhang, Z., Zhao, L., Huang, L., Yang, X. L., Tang, J., \& Feng, S. S. (2013). Pharmaceutical nanotechnology for oral delivery of anticancer drugs. Advanced Drug Delivery Reviews, 65(6), 880-890.

[14] Schroeder, A., Heller, D. A., Winslow, M. M., Dahlman, J. E., Pratt, G. W., Langer, R., Jacks, T., \& Anderson, D. G. (2012). Treating metastatic cancer with nanotechnology. Nature Reviews Cancer, 12(1), 39-50.

[15] Ferrari, M. (2005). Cancer nanotechnology: opportunities and challenges. Nature Reviews Cancer, 5(3), 161-171.

[16] Farokhzad, O. C., \& Langer, R. (2009). Impact of nanotechnology on drug delivery. ACS Nano, 3(1), 16-20.

[17] Sinha, R., Kim, G. J., Nie, S., \& Shin, D. M. (2006). Nanotechnology in cancer therapeutics: bioconjugated nanoparticles for drug delivery. Molecular Cancer Therapeutics, 5(8), 1909-1917.

[18] Prabhakar, U., Maeda, H., Jain, R. K., Sevick-Muraca, E. M., Zamboni, W., Farokhzad, O. C., Barry, S. T., Gabizon, A., Grodzinski, P.,\& Blakey, D. C. (2013). Challenges and key considerations of the enhanced permeability and retention effect for nanomedicine drug delivery in oncology. Cancer Research, 73(8), 2412-2417.

[19] Zhao, Y. X., Shaw, A., Zeng, X., Benson, E., Nystrom, A. M., \& Hogberg, B. (2012). DNA origami delivery system for cancer therapy with tunable release properties. ACS Nano, 6(10), 8684-8691.

[20] Peiris, P. M., Bauer, L., Toy, R., Tran, E., Pansky, J., Doolittle, E., Schmidt, E., Hayden, E., Mayer, A., Keri, R. A., Griswold, M. A., \& Karathanasis, E. (2012). Enhanced delivery of chemotherapy to tumors using a multicomponent nanochain with radiofrequency-tunable drug release. ACS Nano, 6(5), 4157-4168. 
[21] Oh, S. S., Lee, B. F., Leibfarth, F. A., Eisenstein, M., Robb, M. J., Lynd, N. A., Hawker, C. J., \& Soh, H. T. (2014). Synthetic aptamer-polymer hybrid constructs for programmed drug delivery into specific target cells. Journal of the American Chemical Society, 136(42), 15010-15015.

[22] Zhang, Q., Ko, N. R., \& Oh, J. K. (2012). Recent advances in stimuli-responsive degradable block copolymer micelles: synthesis and controlled drug delivery applications. Chemical Communications, 48(61), 7542-7552.

[23] Binauld, S., Scarano, W., \& Stenzel, M. H. (2012). pH-Triggered release of platinum drugs conjugated to micelles via an acid-cleavable linker. Macromolecules, 45(17), 69896999.

[24] Schmaljohann, D. (2006). Thermo-and pH-responsive polymers in drug delivery. Advanced Drug Delivery reviews, 58(15), 1655-1670.

[25] Cheng, R., Feng, F., Meng, F., Deng, C., Feijen, J., \& Zhong, Z. (2011). Glutathioneresponsive nano-vehicles as a promising platform for targeted intracellular drug and gene delivery. Journal of Controlled release, 152(1), 2-12.

[26] Sun, W., Jiang, T., Lu, Y., Reiff, M., Mo, R., \& Gu, Z. (2014). Cocoon-Like SelfDegradable DNA Nanoclew for Anticancer Drug Delivery. Journal of the American Chemical Society, 136(42), 14722-14725.

[27] Judd, J., Ho, M. L., Tiwari, A., Gomez, E. J., Dempsey, C., Van Vliet, K., Igoshin, O. A., Silberg, J. J., Agbandje-McKenna, M. \& Suh, J. (2014). Tunable protease-activatable virus nanonodes. ACS Aano, 8(5), 4740-4746.

[28] Wang, C., Li, Z., Cao, D., Zhao, Y. L., Gaines, J. W., Bozdemir, O. A., Ambrogio, M. W., Frasconi, M., Botros, Y. Y., Zink, J. I., \& Stoddart, J. F. (2012). Stimulated release of size-selected cargos in succession from mesoporous silica nanoparticles. Angewandte Chemie International Edition, 51(22), 5460-5465.

[29] Liao, L., Liu, J., Dreaden, E. C., Morton, S. W., Shopsowitz, K. E., Hammond, P. T., \& Johnson, J. A. (2014). A convergent synthetic platform for single-nanoparticle combination cancer therapy: ratiometric loading and controlled release of cisplatin, doxorubicin, and camptothecin. Journal of the American Chemical Society, 136(16), 5896-5899.

[30] Cho, K., Wang, X. U., Nie, S., \& Shin, D. M. (2008). Therapeutic nanoparticles for drug 
delivery in cancer. Clinical Cancer Research, 14(5), 1310-1316.

[31] Chen, J., Glaus, C., Laforest, R., Zhang, Q., Yang, M., Gidding, M., Welch, M. J., \& Xia, Y. (2010). Gold nanocages as photothermal transducers for cancer treatment.Small, 6(7), 811-817.

[32] Z. Chen , L. Ma , Y. Liu , C. Chen, Applications of functionalized fullerenes in tumor theranostics, Theranostics 2 (2012) 238-250.

[33] Zhang, Z., Wang, L., Wang, J., Jiang, X., Li, X., Hu, Z., Ji, Y., Wu, X., \& Chen, C. (2012). Mesoporous silica-coated gold nanorods as a light-mediated multifunctional theranostic platform for cancer treatment. Advanced Materials, 24(11), 1418-1423.

[34] von Maltzahn, G., Park, J. H., Agrawal, A., Bandaru, N. K., Das, S. K., Sailor, M. J., \& Bhatia, S. N. (2009). Computationally guided photothermal tumor therapy using longcirculating gold nanorod antennas. Cancer Research, 69(9), 3892-3900.

[35] Tao, Y., Ju, E., Liu, Z., Dong, K., Ren, J., \& Qu, X. (2014). Engineered, self-assembled near-infrared photothermal agents for combined tumor immunotherapy and chemophotothermal therapy. Biomaterials, 35(24), 6646-6656.

[36] Hauck, T. S., Jennings, T. L., Yatsenko, T., Kumaradas, J. C., \& Chan, W. C. (2008). Enhancing the toxicity of cancer chemotherapeutics with gold nanorod hyperthermia. Advanced Materials, 20(20), 3832-3838.

[37] Al-Lazikani, B., Banerji, U., \& Workman, P. (2012). Combinatorial drug therapy for cancer in the post-genomic era. Nature biotechnology, 30(7), 679-692.

[38] Marusyk, A., Almendro, V., \& Polyak, K. (2012). Intra-tumour heterogeneity: a looking glass for cancer? Nature Reviews Cancer, 12(5), 323-334.

[39] Junttila, M. R., \& de Sauvage, F. J. (2013). Influence of tumour micro-environment heterogeneity on therapeutic response. Nature, 501(7467), 346-354.

[40] Trédan, O., Galmarini, C. M., Patel, K., \& Tannock, I. F. (2007). Drug resistance and the solid tumor microenvironment. Journal of the National Cancer Institute, 99(19), 14411454.

[41] Quail, D. F., \& Joyce, J. A. (2013). Microenvironmental regulation of tumor progression and metastasis. Nature Medicine, 19(11), 1423-1437.

[42] Gottesman, M. M. (2002). Mechanisms of cancer drug resistance. Annual Review of Medicine, 53(1), 615-627. 
[43] Longley, D. B., \& Johnston, P. G. (2005). Molecular mechanisms of drug resistance. The Journal of Pathology, 205(2), 275-292.

[44] Baguley, B. C. (2010). Multiple drug resistance mechanisms in cancer. Molecular Biotechnology, 46(3), 308-316.

[45] Tsuruo, T., Naito, M., Tomida, A., Fujita, N., Mashima, T., Sakamoto, H., \& Haga, N. (2003). Molecular targeting therapy of cancer: drug resistance, apoptosis and survival signal. Cancer Science, 94(1), 15-21.

[46] Holohan, C., Van Schaeybroeck, S., Longley, D. B., \& Johnston, P. G. (2013). Cancer drug resistance: an evolving paradigm. Nature Reviews Cancer, 13(10), 714-726.

[47] Yang, L., Moss, T., Mangala, L. S., Marini, J., Zhao, H., Wahlig, S., Armaiz-Pena, G., Jiang, D., Achreja, A., Win, J., Roopaimoole, R., Rodriguez-Aguayo, C., Mercado-Uribe, I., Lopez-Berestein, G., Liu, J., Tsukamoto, T., Sood, A. K., Ram, P. T., \& Nagrath, D. (2014). Metabolic shifts toward glutamine regulate tumor growth, invasion and bioenergetics in ovarian cancer. Molecular Systems Biology, 10(5).

[48] Choi, S., Henderson, M. J., Kwan, E., Beesley, A. H., Sutton, R., Bahar, A. Y., Giles, J., Venn, N. C., Pozza, L. D., Baker, D. L., Marshall, G. M., Kees, U. R., Haber, M., \& Norris, M. D. (2007). Relapse in children with acute lymphoblastic leukemia involving selection of a preexisting drug-resistant subclone. Blood, 110(2), 632-639.

[49] Howard, P. L., Chia, M. C., Del Rizzo, S., Liu, F. F., \& Pawson, T. (2003). Redirecting tyrosine kinase signaling to an apoptotic caspase pathway through chimeric adaptor proteins. Proceedings of the National Academy of Sciences of the United States of America, 100(20), 11267-11272.

[50] Michor, F., \& Polyak, K. (2010). The origins and implications of intratumor heterogeneity. Cancer Prevention Research, 3(11), 1361-1364.

[51] Park, S. Y., Gönen, M., Kim, H. J., Michor, F., \& Polyak, K. (2010). Cellular and genetic diversity in the progression of in situ human breast carcinomas to an invasive phenotype. The Journal of Clinical Investigation, 120(2), 636.

[52] Almendro, V., Marusyk, A., \& Polyak, K. (2013). Cellular heterogeneity and molecular evolution in cancer. Annual Review of Pathology: Mechanisms of Disease, 8, 277-302.

[53] Ding, L., Ley, T. J., Larson, D. E., Miller, C. A., Koboldt, D. C., Welch, J. S., Ritchey, J, K., Young, M. A., Lamprecht, T., McLellan, M. D,. McMichael, J. F., Wallis, J. W., Lu, 
C., Shen, D., Harris, C. C., Dooling, D, J., Fulton, R. S., Fulton, L. L., Chen, K., Schmidt, H., Kalicki-Veizer, J., Magrini, V. J., Cook, L., McGrath, S. D., Vickery, T. L., Wendl, M. C., Heath, S., Watson, M. A., Link, D. C., Tomasson, M. H., Shannon, W. D., Payton, J. E., Kulkarni, S., Westervelt, P., Walter, M. J., Graubert, T. A., Mardis, E. R., Wilson, R. K., \& DiPersio, J. F. (2012). Clonal evolution in relapsed acute myeloid leukaemia revealed by whole-genome sequencing. Nature, 481(7382), 506-510.

[54] Kleppe, M., \& Levine, R. L. (2014). Tumor heterogeneity confounds and illuminates: assessing the implications. Nature Medicine, 20(4), 342-344.

[55] Navin, N. E. (2014). Tumor evolution in response to chemotherapy: phenotype versus genotype. Cell Reports, 6(3), 417-419.

[56] Potti, A., Dressman, H. K., Bild, A., Riedel, R. F., Chan, G., Sayer, R., Cragun, J., Cottrill, H., Kelley, M. J., Petersen, R., Harpole, D., Marks, J., Berchuck, A., Ginsburg, G. S., Febbo, P., Lancaster, J., \& Nevins, J. R. (2006). Genomic signatures to guide the use of chemotherapeutics. Nature Medicine, 12(11), 1294-1300.

[57] Lawrence, M. S., Stojanov, P., Polak, P., Kryukov, G. V., Cibulskis, K., Sivachenko, A., Carter, S. L., Stewart, C., Mermel, C. H., Roberts, S. A., Kiezun, A., Hammerman, P. S., McKenna, A., Drier, Y., Zou, L., Ramos, A. H., Pugh, T. J., Stransky, N., Helman, E., Kim, J., Sougnez, C., Ambrogio, L., Nickerson, E., Shefler, E., Cortés, M. L., Auclair, D., Saksena, G., Voet, D., Noble, M., DiCara, D., Lin, P., Lichtenstein, L., Heiman, DI., Fennell, T., Imielinski, M., Hernandez, B., Hodis, E., Baca, S., Dulak, AM., Lohr, J., Landau, D. A., Wu, C. J., Melendez-Zajgla, J., Hidalgo-Miranda, A., Koren, A., McCarroll, SA., Mora, J., Lee, RS., Crompton, B., Onofrio, R., Parkin, M., Winckler, W., Ardlie, K., Gabriel, S. B., Roberts, CW., Biegel, J. A., Stegmaier, K., Bass, A. J., Garraway, L. A., Meyerson, M., Golub, T. R., Gordenin, D. A., Sunyaev, S., Lander, ES., Getz, G. \& Onofrio, R. (2013). Mutational heterogeneity in cancer and the search for new cancer-associated genes. Nature, 499(7457), 214-218.

[58] Seguin, L., Kato, S., Franovic, A., Camargo, M. F., Lesperance, J., Elliott, K. C., Yebra, M., Mielgo, A., Lowy, A. M., Husain, H., Cascone, T., Diao, L., Wang, J., Wistuba, II., Heymach, J. V., Lippman, S. M., Desgrosellier, JS., Anand, S., Weis, S. M \& Cheresh, D. A. (2014). An integrin $\beta 3-$ KRAS-RalB complex drives tumour stemness and resistance to EGFR inhibition. Nature Cell Biology, 16(5), 457-468. 
[59] Lohr, J. G., Stojanov, P., Carter, S. L., Cruz-Gordillo, P., Lawrence, M. S., Auclair, D., Sougnez, C., Knoechel, B., Gould, J., Saksena, G., Cibulskis, K., McKenna, A., Chapman, M. A., Straussman, R., Levy, J., Perkins, L. M., Keats, J. J., Schumacher, S. E., Rosenberg, M., Multiple Myeloma Research Consortium., Getz, G., \& Golub, T. R., (2014). Widespread genetic heterogeneity in multiple myeloma: implications for targeted therapy. Cancer Cell, 25(1), 91-101.

[60] Rosell, R., Carcereny, E., Gervais, R., Vergnenegre, A., Massuti, B., Felip, E., Palmero, R., Garcia-Gomez, R., Pallares, C., Sanchez, J. M., Porta, R., Cobo, M., Garrido, P., Longo, F., Moran, T., Insa, A., De, Marinis, F., Corre, R., Bover, I., Illiano, A., Dansin, E., de, Castro, J., Milella, M., Reguart, N., Altavilla, G., Jimenez, U., Provencio, M., Moreno, MA., Terrasa, J., Muñoz-Langa, J., Valdivia, J., Isla, D., Domine, M., Molinier, O., Mazieres, J., Baize, N., Garcia-Campelo, R., Robinet, G., Rodriguez-Abreu, D., Lopez-Vivanco, G., Gebbia, V., Ferrera-Delgado, L., Bombaron, P., Bernabe, R., Bearz, A., Artal, A., Cortesi, E., Rolfo, C., Sanchez-Ronco, M., Drozdowskyj, A., Queralt, C., de, Aguirre, I., Ramirez, J. L., Sanchez, J. J., Molina, MA., Taron, M., Paz-Ares, L; Spanish Lung Cancer Group in collaboration with Groupe Français de PneumoCancérologie \& Associazione Italiana Oncologia Toracica (2012). Erlotinib versus standard chemotherapy as first-line treatment for European patients with advanced EGFR mutation-positive non-small-cell lung cancer (EURTAC): a multicentre, open-label, randomised phase 3 trial. The Lancet Oncology, 13(3), 239-246.

[61] Robert, N. J., Diéras, V., Glaspy, J., Brufsky, A. M., Bondarenko, I., Lipatov, O. N., Perez, E. A., Yardley, D. A., Chan, S. Y., Zhou, X., Phan, S. C., \& O'Shaughnessy, J. (2011). RIBBON-1: Randomized, double-blind, placebo-controlled, phase III trial of chemotherapy with or without bevacizumab for first-line treatment of human epidermal growth factor receptor 2-negative, locally recurrent or metastatic breast cancer. Journal of Clinical Oncology,29(10), 1252-1260

[62] Szakács, G., Paterson, J. K., Ludwig, J. A., Booth-Genthe, C., \& Gottesman, M. M. (2006). Targeting multidrug resistance in cancer. Nature Reviews Drug Discovery, 5(3), 219-234

[63] Gottesman, M. M., Fojo, T., \& Bates, S. E. (2002). Multidrug resistance in cancer: role of ATP-dependent transporters. Nature Reviews Cancer, 2(1), 48-58. 
[64] Xu, L., Pirollo, K. F., \& Chang, E. H. (2001). Tumor-targeted p53-gene therapy enhances the efficacy of conventional chemo/radiotherapy. Journal of Controlled Release, 74(1), 115-128.

[65] Bild, A. H., Yao, G., Chang, J. T., Wang, Q., Potti, A., Chasse, D., Joshi, M. B., Harpole, D., Lancaster, J. M., Berchuck, A., Olson, Jr., J. A., Marks, J. R., Dressman, H. K., West, J., \& Nevins, J. R. (2006). Oncogenic pathway signatures in human cancers as a guide to targeted therapies. Nature, 439(7074), 353-357.

[66] Stark, D., Nankivell, M., Pujade-Lauraine, E., Kristensen, G., Elit, L., Stockler, M., Hilpert, F., Cervantes, A., Brown, J., Lanceley, A., Velikova, G., Sabate, E., Pfisterer, J., Carey, M. S., Beale, P., Qian, W., Swart, A. M., Oza, A., \& Perren, T. (2013). Standard chemotherapy with or without bevacizumab in advanced ovarian cancer: quality-of-life outcomes from the International Collaboration on Ovarian Neoplasms (ICON7) phase 3 randomised trial. The lancet oncology, 14(3), 236-243.

[67] Alberts, S. R., Sargent, D. J., Nair, S., Mahoney, M. R., Mooney, M., Thibodeau, S. N., Smyrk, T. C., Sinicrope, F. A., Chan, E., Gill, S., Kahlenberg, M. S., Shields, A. F., Quesenberry, J. T., Webb, T. A., Farr Jr., G. H., Pockaj, B. A., Grothey, A., \& Goldberg, R. M. (2012). Effect of Oxaliplatin, Fluorouracil, and Leucovorin With or Without Cetuximab on Survival Among Patients With Resected Stage III Colon Cancer: A Randomized Trial. JAMA: The Journal of the American Medical Association, 307(13), 1383-1393.

[68] Blackwell, K. L., Burstein, H. J., Storniolo, A. M., Rugo, H. S., Sledge, G., Aktan, G., Ellis, C., Florance, A., Vukelja, S., Bischoff, J., Baselga, J., \& O'Shaughnessy, J. (2012). Overall survival benefit with lapatinib in combination with trastuzumab for patients with human epidermal growth factor receptor 2-positive metastatic breast cancer: Final results from the EGF104900 study. Journal of Clinical Oncology, 30(21), 2585-2592.

[69] Herbst, R. S., Sun, Y., Eberhardt, W. E. E., Germonpré, P., Saijo, N., Zhou, C., Wang, J., Li, L., Kabbinavar, F., Ichinose, Y., Qin, S., Zhang, L., Biesma, B., Heymach, J. V., Langmuir, P., Kennedy, SJ., Tada, H, Johnson, B. E. (2010). Vandetanib plus docetaxel versus docetaxel as second-line treatment for patients with advanced non-small-cell lung cancer (ZODIAC): a double-blind, randomised, phase 3 trial. The Lancet Oncology,11(7), 619-626. 
[70] Piccart, M., Hortobagyi, G. N., Campone, M., Pritchard, K. I., Lebrun, F., Ito, Y., Noguchi, S., Perez, A., Rugo, H. S., Deleu, I., Burris, H. A 3rd., Provencher, L., Neven, P., Gnant, M., Shtivelband, M., Wu, C., Fan, J., Fen,g W., Taran, T., \& Baselga, J. (2014). Everolimus plus exemestane for hormone-receptor-positive, human epidermal growth factor receptor-2-negative advanced breast cancer: overall survival results from BOLERO-2. Annals of Oncology, mdu456.

[71] Stupp, R., Hegi, M. E., Gorlia, T., Erridge, S. C., Perry, J., Hong, Y. K., Aldape, K. D., Lhermitte, B., Pietsch, T., Grujicic, D., Steinbach, J. P., Wick, W., Tarnawski, R., Nam, D. H., Hau, P., Weyerbrock, A., Taphoorn, M. J., Shen, CC., Rao, N., Thurzo, L., Herrlinger, U., Gupta, T., Kortmann, R. D., Adamska, K., McBain, C., Brandes, A. A., Tonn, J. C., Schnell, O., Wiegel, T., Kim, C. Y., Nabors, L. B., Reardon, D. A., van den Bent, M. J., Hicking, C., Markivskyy, A., Picard, M., Weller, M., European Organisation for Research and Treatment of Cancer, (EORTC); \& CENTRIC study team. (2014). Cilengitide combined with standard treatment for patients with newly diagnosed glioblastoma with methylated MGMT promoter (CENTRIC EORTC 26071-22072 study): a multicentre, randomised, open-label, phase 3 trial. The Lancet Oncology, 15(10), 1100-1108.

[72] Elter, T., Gercheva-Kyuchukova, L., Pylylpenko, H., Robak, T., Jaksic, B., Rekhtman, G., Kyrcz-Krzemień, S., Vatutin, M., Wu, J., Sirard, C., Hallek, M., \& Engert, A. (2011). Fludarabine plus alemtuzumab versus fludarabine alone in patients with previously treated chronic lymphocytic leukaemia: a randomised phase 3 trial. The Lancet Oncology, 12(13), 1204-1213.

[73] Zonder, J. A., Crowley, J., Hussein, M. A., Bolejack, V., Moore, D. F., Whittenberger, B. F., Abidi, M. H., Durie, B. G., Barlogie, B. (2010). Lenalidomide and high-dose dexamethasone compared with dexamethasone as initial therapy for multiple myeloma: a randomized Southwest Oncology Group trial (S0232). Blood,116(26), 5838-5841.

[74] Hauschild, A., Agarwala, S. S., Trefzer, U., Hogg, D., Robert, C., Hersey, P., Eggermont, A., Grabbe, S., Gonzalez, R., Gille, J., Peschel, C., Schadendorf, D., Garbe, C., O'Day, S., Daud, A., White, J. M., Xia, C., Patel, K., Kirkwood, J. M., Keilholz, U., (2009) Results of a phase III, randomized, placebo-controlled study of sorafenib in combination with carboplatin and paclitaxel as second-line treatment in patients with unresectable 
stage III or stage IV melanoma. The Journal of Clinical Oncology,, 27(17):2823-30.

[75] Finn, R. S., Press, M. F., Dering, J., Arbushites, M., Koehler, M., Oliva, C., Williams, L. S., \& Di Leo, A.(2009) Estrogen receptor, progesterone receptor, human epidermal growth factor receptor 2 (HER2), and epidermal growth factor receptor expression and benefit from lapatinib in a randomized trial of paclitaxel with lapatinib or placebo as firstline treatment in HER2-negative or unknown metastatic breast cancer. The Journal of Clinical Oncology, 27(24):3908-15.

[76] Schadendorf, D., Amonkar, M. M., Stroyakovskiy, D., Levchenko, E., Gogas, H., de Braud, F., Grob, J. J., Bondarenko, I., Garbe, C., Lebbe, C., Larkin, J., Chiarion-Sileni, V., Millward, M., Arance, A., Mandalà, M., Flaherty, K. T., Nathan, P., Ribas, A., Robert, C., Casey, M., DeMarini, D. J., Irani, J. G., Aktan, G., \&, Long, G., V. (2015) Health-related quality of life impact in a randomised phase III study of the combination of dabrafenib and trametinib versus dabrafenib monotherapy in patients with BRAF V600 metastatic melanoma. European Journal of Cancer, 51(7):833-40.

[77] Pujade-Lauraine, E., Hilpert, F., Weber, B., Reuss, A., Poveda, A., Kristensen, G., Sorio, R., Vergote, I., Witteveen, P., Bamias, A., Pereira, D., Wimberger, P., Oaknin, A., Mirza, M. R., Follana, P., Bollag, D., \& Ray-Coquard, I. (2014). Bevacizumab combined with chemotherapy for platinum-resistant recurrent ovarian cancer: the AURELIA open-label randomized phase III trial. Journal of Clinical Oncology, 32(13), 1302-1308.

[78] Zhang, H., \& Burrows, F. (2004). Targeting multiple signal transduction pathways through inhibition of Hsp90. Journal of Molecular Medicine, 82(8), 488-499.

[79] Faivre, S., Djelloul, S., \& Raymond, E. (2006, August). New paradigms in anticancer therapy: targeting multiple signaling pathways with kinase inhibitors. In Seminars in oncology (Vol. 33, No. 4, pp. 407-420). WB Saunders.

[80] Friday, B. B., \& Adjei, A. A. (2008). Advances in targeting the Ras/Raf/MEK/Erk mitogen-activated protein kinase cascade with MEK inhibitors for cancer therapy. Clinical Cancer Research, 14(2), 342-346.

[81] Bozic, I., Allen, B., \& Nowak, M. A. (2012). Dynamics of targeted cancer therapy. Trends in Molecular Medicine, 18(6), 311-316.

[82] Jänne, P. A., Shaw, A. T., Pereira, J. R., Jeannin, G., Vansteenkiste, J., Barrios, C., Franke, F. A., Grinsted, L., Zazulina, V., Smith, P., Smith, I., \& Crinò, L. (2013). 
Selumetinib plus docetaxel for KRAS-mutant advanced non-small-cell lung cancer: a randomised, multicentre, placebo-controlled, phase 2 study. The Lancet Oncology, 14(1), 38-47.

[83] Kobayashi, S., Boggon, T. J., Dayaram, T., Jänne, P. A., Kocher, O., Meyerson, M., Johnson, B. E., Eck, M. J., Tenen, D. G., \& Halmos, B. (2005). EGFR mutation and resistance of non-small-cell lung cancer to gefitinib. New England Journal of Medicine, 352(8), 786-792.

[84] Paez, J. G., Jänne, P. A., Lee, J. C., Tracy, S., Greulich, H., Gabriel, S., Herman, P., Kaye, F. J., Lindeman, N., Boggon, T. J., Naoki, K., Sasaki, H., Fujii, Y., Eck, M. J., Sellers, W. R., Johnson, B. E \& Meyerson, M. (2004). EGFR mutations in lung cancer: correlation with clinical response to gefitinib therapy. Science, 304(5676), 1497-1500.

[85] Pao, W., Miller, V., Zakowski, M., Doherty, J., Politi, K., Sarkaria, I., Singh, B., Heelan, R., Rusch, V., Fulton, L., Mardis, E., Kupfer, D., Wilson, R., Kris, M \& Varmus, H. (2004). EGF receptor gene mutations are common in lung cancers from "never smokers" and are associated with sensitivity of tumors to gefitinib and erlotinib. Proceedings of the National Academy of Sciences of the United States of America, 101(36), 13306-13311.

[86] Shigematsu, H., Lin, L., Takahashi, T., Nomura, M., Suzuki, M., Wistuba, I. I., Fong, K. M., Lee, H., Toyooka, S., Shimizu, N., Fujisawa, T., Feng, Z., Roth, J. A., Herz, J., Minna, J. D \& Gazdar, A. F. (2005). Clinical and biological features associated with epidermal growth factor receptor gene mutations in lung cancers. Journal of the National Cancer Institute, 97(5), 339-346.

[87] Misale, S., Yaeger, R., Hobor, S., Scala, E., Janakiraman, M., Liska, D., Valtorta, E., Schiavo, R., Buscarino, M., Siravegna, G., Bencardino, K., Cercek, A., Chen, C. T., Veronese, S., Zanon, C., Sartore-Bianchi, A., Gambacorta, M., Gallicchio, M., Vakiani, E., Boscaro, V., Medico, E., Weiser, M., Siena, S., Di, Nicolantonio, F., Solit, D., \& Bardelli, A. (2012). Emergence of KRAS mutations and acquired resistance to antiEGFR therapy in colorectal cancer. Nature, 486(7404), 532-536.

[88] Nakagawa, T., Takeuchi, S., Yamada, T., Nanjo, S., Ishikawa, D., Sano, T., Kita, K., Nakamura, T., Matsumoto, K., Suda, K., Mitsudomi, T., Sekido, Y., Uenaka, T., \& Yano, S. (2012). Combined therapy with mutant-selective EGFR inhibitor and Met kinase inhibitor for overcoming erlotinib resistance in EGFR-mutant lung cancer. Molecular 
Cancer Therapeutics, 11(10), 2149-2157.

[89] Ferrara, N. (2002). VEGF and the quest for tumour angiogenesis factors. Nature Reviews Cancer, 2(10), 795-803.

[90] Ellis, L. M., \& Hicklin, D. J. (2008). VEGF-targeted therapy: mechanisms of anti-tumour activity. Nature Reviews Cancer, 8(8), 579-591.

[91] Hilger, R. A., Scheulen, M. E., \& Strumberg, D. (2002). The Ras-Raf-MEK-ERK pathway in the treatment of cancer. Oncology Research and Treatment, 25(6), 511-518.

[92] Flaherty, K. T., Infante, J. R., Daud, A., Gonzalez, R., Kefford, R. F., Sosman, J., Omid Hamid, O., Schuchter, L., Cebon, J., Ibrahim, N., Kudchadkar, R., Burris, III, H. A., Falchook, G., Algazi, A., Lewis, K., Long, G. V., Puzanov, I., Lebowitz, P., Singh, A., Little, S., Sun, P., Allred, A., Ouellet, D., Kim, K. B., Patel, K.,. \& Weber, J. (2012). Combined BRAF and MEK inhibition in melanoma with BRAF V600 mutations. New England Journal of Medicine, 367(18), 1694-1703.

[93] Greger, J. G., Eastman, S. D., Zhang, V., Bleam, M. R., Hughes, A. M., Smitheman, K. N., Dickerson, S. H, Laquerre, S. G, Liu, L, \& Gilmer, T. M. (2012). Combinations of BRAF, MEK, and PI3K/mTOR inhibitors overcome acquired resistance to the BRAF inhibitor GSK2118436 dabrafenib, mediated by NRAS or MEK mutations. Molecular Cancer Therapeutics, 11(4), 909-920.

[94] Prahallad, A., Sun, C., Huang, S., Di Nicolantonio, F., Salazar, R., Zecchin, D., Beijersbergen, R. L, Bardelli, A, \& Bernards, R. (2012). Unresponsiveness of colon cancer to BRAF (V600E) inhibition through feedback activation of EGFR. Nature, 483(7388), 100-103

[95] Villanueva, J., Vultur, A., Lee, J. T., Somasundaram, R., Fukunaga-Kalabis, M., Cipolla, A. K., Wubbenhorst, B., Xu, X., Gimotty, P. A., Kee, D., Santiago-Walker, A. E., Letrero, R., D'Andrea, K., Pushparajan, A., Hayden, J. E., Brown, K. D., Laquerre, S., McArthur, G. A., Sosman, J. A., Nathanson, K. L, \& Herlyn, M. (2010). Acquired resistance to BRAF inhibitors mediated by a RAF kinase switch in melanoma can be overcome by cotargeting MEK and IGF-1R/PI3K. Cancer Cell, 18(6), 683-695.

[96] Long, G. V., Stroyakovskiy, D., Gogas, H., Levchenko, E., de, Braud, F., Larkin, J., Garbe, C., Jouary, T., Hauschild, A., Grob, J. J., Chiarion, Sileni, V., Lebbe, C., Mandalà, M., Millward, M., Arance, A., Bondarenko, I., Haanen, J. B., Hansson, J., Utikal, J., 
Ferraresi, V., Kovalenko, N., Mohr, P., Probachai, V., Schadendorf, D., Nathan, P., Robert, C., Ribas, A., DeMarini, D. J., Irani, J. G., Casey, M., Ouellet, D., Martin, A. M., Le, N., Patel, K., \& Flaherty K. (2014) Combined BRAF and MEK inhibition versus BRAF inhibition alone in melanoma. New England Journal of Medicine, 371(20),187788

[97] Le Gouill, S., Podar, K., Amiot, M., Hideshima, T., Chauhan, D., Ishitsuka, K., Kumar, S., Raje, N., Richardson, P. G., Harousseau, J. L., \& Anderson, K. C. (2004). VEGF induces Mcl-1 up-regulation and protects multiple myeloma cells against apoptosis. Blood, 104(9), 2886-2892.

[98] Pei, X. Y., Dai, Y., Felthousen, J., Chen, S., Takabatake, Y., Zhou, L., Youssefian, L. E., Sanderson, M. W., Bodie, W. W., Kramer, L. B., Orlowski, R. Z., \& Grant, S. (2014). Circumvention of Mcl-1-dependent drug resistance by simultaneous Chk1 and MEK1/2 inhibition in human multiple myeloma cells. PloS One, 9(3).

[99] Ashwell, S., \& Zabludoff, S. (2008). DNA damage detection and repair pathwaysrecent advances with inhibitors of checkpoint kinases in cancer therapy. Clinical Cancer Research, 14(13), 4032-4037.

[100]Luo, J., Manning, B. D., \& Cantley, L. C. (2003). Targeting the PI3K-Akt pathway in human cancer: rationale and promise. Cancer cell, 4(4), 257-262.

[101]Cully, M., You, H., Levine, A. J., \& Mak, T. W. (2006). Beyond PTEN mutations: the PI3K pathway as an integrator of multiple inputs during tumorigenesis. Nature Reviews Cancer, 6(3), 184-192.

[102] Cantley, L. C. (2002). The phosphoinositide 3-kinase pathway. Science,296(5573), 16551657.

[103] Courtney, K. D., Corcoran, R. B., \& Engelman, J. A. (2010). The PI3K pathway as drug target in human cancer. Journal of Clinical Oncology, 28(6), 1075-1083.

[104]LoPiccolo, J., Blumenthal, G. M., Bernstein, W. B., \& Dennis, P. A. (2008). Targeting the PI3K/Akt/mTOR pathway: effective combinations and clinical considerations. Drug Resistance Updates, 11(1), 32-50.

[105] Stommel, J. M., Kimmelman, A. C., Ying, H., Nabioullin, R., Ponugoti, A. H., Wiedemeyer, R., Stegh, A. H., Bradner, J. E., Ligon, K. L., Brennan, C., Chin, L., \& DePinho, R. A. (2007). Coactivation of receptor tyrosine kinases affects the response of 
tumor cells to targeted therapies. Science,318(5848), 287-290.

[106] Vara, J. Á. F., Casado, E., de Castro, J., Cejas, P., Belda-Iniesta, C., \& González-Barón, M. (2004). PI3K/Akt signalling pathway and cancer. Cancer Treatment Reviews, 30(2), 193-204.

[107] Vora, S. R., Juric, D., Kim, N., Mino-Kenudson, M., Huynh, T., Costa, C.,, Lockerman, E. L., Pollack, S. F., Liu, M., Li, X., Lehar, J., Wiesmann, M., Wartmann, M., Chen, Y., Cao, Z. A., Pinzon-Ortiz, M., Kim, S., Schlegel, R., Huang, A,, \& Engelman, J. A. (2014). CDK 4/6 inhibitors sensitize PIK3CA mutant breast cancer to PI3K inhibitors. Cancer Cell, 26(1), 136-149.

[108] Shimizu, T., Tolcher, A. W., Papadopoulos, K. P., Beeram, M., Rasco, D. W., Smith, L. S., Gunn, S., Smetzer, L., Mays, TA., Kaiser, B., Wick, M. J., Alvarez, C., Cavazos, A., Mangold, G. L, \& Patnaik, A. (2012). The clinical effect of the dual-targeting strategy involving PI3K/AKT/mTOR and RAS/MEK/ERK pathways in patients with advanced cancer. Clinical Cancer Research, 18(8), 2316-2325

[109]Chappell, W. H., Steelman, L. S., Long, J. M., Kempf, R. C., Abrams, S. L., Franklin, R. A., Bäsecke, J., Stivala, F., Donia, M., Fagone, P., Malaponte, G., Mazzarino, M. C., Nicoletti, F., Libra, M., Maksimovic-Ivanic, D., Mijatovic, S., Montalto, G., Cervello, M., Laidler, P., Milella, M., Tafuri, A., Bonati, A., Evangelisti, C., Cocco, L., Martelli, A. M,, \& McCubrey, J. A. (2011). Ras/Raf/MEK/ERK and PI3K/PTEN/Akt/mTOR inhibitors: rationale and importance to inhibiting these pathways in human health. Oncotarget, 2(3), 135.

[110]Fruman, David A., and Christian Rommel. "PI3K and cancer: lessons, challenges and opportunities." Nature reviews Drug discovery 13.2 (2014): 140-156.

[111]Takai, M., Nakagawa, T., Tanabe, A., Terai, Y., Ohmichi, M., \& Asahi, M. (2015). Crosstalk between PI3K and Ras pathways via protein phosphatase 2A in human ovarian clear cell carcinoma. Cancer Biology \& Therapy, 16(2), 325-335.

[112]Hu, S., Fu, W., Xu, W., Yang, Y., Cruz, M., Berezov, S. D., Jorissen, D., Takeda, H., \& Zhu, W. (2015). Four-in-one antibodies have superior cancer inhibitory activity against EGFR, HER2, HER3, and VEGF through disruption of HER/MET crosstalk. Cancer Research, 75(1), 159-170.

[113]Larsen, A. K., Ouaret, D., El Ouadrani, K., \& Petitprez, A. (2011). Targeting EGFR and 
VEGF (R) pathway cross-talk in tumor survival and angiogenesis. Pharmacology \& Therapeutics, 131(1), 80-90.

[114] Sounni, N. E., \& Noel, A. (2013). Targeting the tumor microenvironment for cancer therapy. Clinical chemistry, 59(1), 85-93.

[115]Ebos, J. M., \& Kerbel, R. S. (2011). Antiangiogenic therapy: impact on invasion, disease progression, and metastasis. Nature Reviews Clinical Oncology, 8(4), 210-221.

[116] Bergers, G., \& Benjamin, L. E. (2003). Tumorigenesis and the angiogenic switch. Nature reviews cancer, 3(6), 401-410.

[117]Barker, H. E., Cox, T. R., \& Erler, J. T. (2012). The rationale for targeting the LOX family in cancer. Nature Reviews Cancer, 12(8), 540-552.

[118]Fukumura, D., \& Jain, R. K. (2007). Tumor microvasculature and microenvironment: targets for anti-angiogenesis and normalization.Microvascular research, 74(2), 72-84.

[119]Bergers, G., Brekken, R., McMahon, G., Vu, T. H., Itoh, T., Tamaki, K., Tanzawa, K.,Thorpe, P., Itohara, S., Werb, Z., \& Hanahan, D. (2000). Matrix metalloproteinase-9 triggers the angiogenic switch during carcinogenesis. Nature cell biology, 2(10), 737-744

[120]Dieci, M. V., Arnedos, M., Andre, F., \& Soria, J. C. (2013). Fibroblast growth factor receptor inhibitors as a cancer treatment: from a biologic rationale to medical perspectives. Cancer discovery, 3(3), 264-279.

[121] Nakazawa, Y., Kawano, S., Matsui, J., Funahashi, Y., Tohyama, O., Muto, H., Nakagawa, T., \& Matsushima, T. (2014). Maximizing the efficacy of anti-angiogenesis cancer therapy: A multi-targeting strategy by tyrosine kinase inhibitors. Cancer Research, 74(19 Supplement), 2980-2980

[122] Schottelius, A. J., \& Dinter, H. (2006). Cytokines, NF- $\kappa B$, microenvironment, intestinal inflammation and cancer. In The Link Between Inflammation and Cancer (pp. 67-87). Springer US.

[123]Ben-Neriah, Y., \& Karin, M. (2011). Inflammation meets cancer, with NF-[kappa] B as the matchmaker. Nature immunology, 12(8), 715-723.

[124]Lowe, J. M., Menendez, D., Bushel, P. R., Shatz, M., Kirk, E. L., Troester, M. A., Garantziotis, S., Tressler, M. B., \& Resnick, M. A. (2014). p53 and NF-кB coregulate proinflammatory gene responses in human macrophages. Cancer research, 74(8), 21822192. 
[125] Aller, M. A., Arias, J. L., Nava, M. P., \& Arias, J. (2004). Posttraumatic inflammation is a complex response based on the pathological expression of the nervous, immune, and endocrine functional systems. Experimental Biology and Medicine, 229(2), 170-181.

[126] Whiteside, T. L. (2008). The tumor microenvironment and its role in promoting tumor growth. Oncogene, 27(45), 5904-5912.

[127]Lança, T., \& Silva-Santos, B. (2012). The split nature of tumor-infiltrating leukocytes: Implications for cancer surveillance and immunotherapy.Oncoimmunology, 1(5), 717725.

[128]Baud, V., \& Karin, M. (2009). Is NF-кB a good target for cancer therapy? Hopes and pitfalls. Nature reviews Drug discovery, 8(1), 33-40.

[129]Bian, Y., Han, J., Kannabiran, V., Mohan, S., Cheng, H., Friedman, J., Zhang, L., VanWaes, C., \& Chen, Z. (2015). MEK Inhibitor PD-0325901 Overcomes Resistance to CK2 Inhibitor CX-4945 and Exhibits Anti-Tumor Activity in Head and Neck Cancer.International Journal of Biological Sciences, 11(4), 411-422. http://doi.org/10.7150/ijbs.10745

[130] Greten, F. R., Arkan, M. C., Bollrath, J., Hsu, L. C., Goode, J., Miething, C., Göktuna, S. I., Neuenhahn, M., Fierer, J., Paxian, S., Van Rooijen, N., Xu, Y., O'Cain, T., Jaffee, B. B., Busch, D. H., Duyster, J., Schmid, R. M., Eckmann, L., \& Karin, M. (2007). NF-кB is a negative regulator of IL-1 $\beta$ secretion as revealed by genetic and pharmacological inhibition of IKK $\beta$. Cell, 130(5), 918-931.

[131]Erez, N., Truitt, M., Olson, P., \& Hanahan, D. (2010). Cancer-associated fibroblasts are activated in incipient neoplasia to orchestrate tumor-promoting inflammation in an NFкB-dependent manner. Cancer cell, 17(2), 135-147.

[132] Scanlan, M. J., Raj, B. K., Calvo, B., Garin-Chesa, P., Sanz-Moncasi, M. P., Healey, J. H., Old, L. J., \& Rettig, W. J. (1994). Molecular cloning of fibroblast activation protein alpha, a member of the serine protease family selectively expressed in stromal fibroblasts of epithelial cancers. Proceedings of the National Academy of Sciences, 91(12), 56575661.

[133]Baronzio, G., Parmar, G., \& Baronzio, M. (2015). Overview of methods for overcoming hindrance to drug delivery to tumors, with special attention to tumor interstitial fluid. Frontiers in oncology, 5. 
[134] Teichgräber, V., Monasterio, C., Chaitanya, K., Boger, R., Gordon, K., Dieterle, T., Jager, D., \& Bauer, S. (2015). Specific inhibition of fibroblast activation protein (FAP)alpha prevents tumor progression in vitro. Advances in Medical Sciences.

[135]Loeffler, M., Krüger, J. A., Niethammer, A. G., \& Reisfeld, R. A. (2009). Targeting tumor-associated fibroblasts improves cancer chemotherapy by increasing intratumoral drug uptake. The Journal of Clinical Investigation, 119(2), 421.

[136] Pistollato, F., Giampieri, F., \& Battino, M. (2015). The use of plant-derived bioactive compounds to target cancer stem cells and modulate tumor microenvironment. Food and Chemical Toxicology, 75, 58-70.

[137]Li, S. Y., Sun, R., Wang, H. X., Shen, S., Liu, Y., Du, X. J., Zhu, Y., \& Jun, W. (2015). Combination therapy with epigenetic-targeted and chemotherapeutic drugs delivered by nanoparticles to enhance the chemotherapy response and overcome resistance by breast cancer stem cells. Journal of Controlled Release, 205, 7-14.

[138] Vidal, S. J., Rodriguez-Bravo, V., Galsky, M., Cordon-Cardo, C., \& DomingoDomenech, J. (2014). Targeting cancer stem cells to suppress acquired chemotherapy resistance. Oncogene, 33(36), 4451-4463.

[139]Zhao, C., Chen, A., Jamieson, C. H., Fereshteh, M., Abrahamsson, A., Blum, J., Kwon, H. Y., Kim, J., Chute, J. P., Rizzieri, D., Munchhof, M., VanArsdale, T., Beachy, P. A., \& Reya, T. (2009). Hedgehog signalling is essential for maintenance of cancer stem cells in myeloid leukaemia. Nature, 458(7239), 776-779.

[140]Lehár, J., Krueger, A. S., Avery, W., Heilbut, A. M., Johansen, L. M., Price, E. R., Rickles R. J., Short, G. F. 3rd, Staunton, J. E., Jin, X., Lee, M. S., Zimmermann, G. R., \& Borisy, A. A. (2009). Synergistic drug combinations tend to improve therapeutically relevant selectivity. Nature Biotechnology, 27(7), 659-666.

[141] Chou, T. C. (2010). Drug combination studies and their synergy quantification using the Chou-Talalay method. Cancer Research, 70(2), 440-446.

[142] Chou, T. C. (1976). Derivation and properties of Michaelis-Menten type and Hill type equations for reference ligands. Journal of theoretical biology, 59(2), 253-276.

[143]Zhao, L., Wientjes, M. G., \& Au, J. L. (2004). Evaluation of combination chemotherapy integration of nonlinear regression, curve shift, isobologram, and combination index analyses. Clinical Cancer Research, 10(23), 7994-8004. 
[144]Jia, J., Zhu, F., Ma, X., Cao, Z. W., Li, Y. X., \& Chen, Y. Z. (2009). Mechanisms of drug combinations: interaction and network perspectives. Nature reviews Drug Discovery, $8(2), 111-128$.

[145]Lee, J. H., \& Nan, A. (2012). Combination drug delivery approaches in metastatic breast cancer. Journal of drug delivery, 2012.

[146] Mayer, L. D., Harasym, T. O., Tardi, P. G., Harasym, N. L., Shew, C. R., Johnstone, S. A., Ramsay, M. C., Bally, M. B., \& Janoff, A. S. (2006). Ratiometric dosing of anticancer drug combinations: controlling drug ratios after systemic administration regulates therapeutic activity in tumor-bearing mice. Molecular cancer therapeutics, 5(7), 1854-1863.

[147] Cristóbal, I., Rincón, R., Manso, R., Caramés, C., Zazo, S., Madoz-Gúrpide, J., Rojo, F., \& García-Foncillas, J. (2015). Deregulation of the PP2A inhibitor SET shows promising therapeutic implications and determines poor clinical outcome in patients with metastatic colorectal cancer. Clinical Cancer Research, 21(2), 347-356.

[148]Cook, K. L., Wärri, A., Soto-Pantoja, D. R., Clarke, P. A., Cruz, M. I., Zwart, A., \& Clarke, R. (2014). Hydroxychloroquine inhibits autophagy to potentiate antiestrogen responsiveness in ER+ breast cancer. Clinical Cancer Research,20(12), 3222-3232.

[149] Shoman, N., Klassen, S., McFadden, A., Bickis, M. G., Torlakovic, E., \& Chibbar, R. (2005). Reduced PTEN expression predicts relapse in patients with breast carcinoma treated by tamoxifen. Modern Pathology, 18(2), 250-259.

[150] Greco, F. and Vicent, M.J. (2009) Combination therapy: opportunities and challenges for polymer-drug conjugates as anticancer nanomedicines. Adv. Drug Deliv. Rev. 61, 12031213

[151]J.L. Arias, Drug targeting strategies in cancer treatment: an overview, Mini Rev. Med. Chem. 11 (2011) 1-17

[152] Ortac, I., Simberg, D., Yeh, Y. S., Yang, J., Messmer, B., Trogler, W. C., Tsien, R. Y., \& Esener, S. (2014). Dual-Porosity Hollow Nanoparticles for the Immunoprotection and Delivery of Nonhuman Enzymes. Nano Letters, 14(6), 3023-3032.

[153] Orive, G., Hernández, R. M., Gascón, A. R., \& Pedraz, J. L. (2005). Micro and nano drug delivery systems in cancer therapy. Cancer Therapy, 3(1), 131-8.

[154]Hanson, J. A.; Chang, C. B.; Graves, S. M.; Li, Z.; Mason, T. G.;Deming, T. J. Nanoscale 
Double Emulsions Stabilized By Single-Component Block Copolypeptides. Nature, 455, 85-88.2008,

[155]Chu, K. S., Schorzman, A. N., Finniss, M. C., Bowerman, C. J., Peng, L., Luft, J. C., Madden, A. J., Wang, A. Z., Zamboni, W. C., \& DeSimone, J. M. (2013). Nanoparticle drug loading as a design parameter to improve docetaxel pharmacokinetics and efficacy. Biomaterials,34(33), 8424-8429.

[156] Soppimath, K. S., Aminabhavi, T. M., Kulkarni, A. R., \& Rudzinski, W. E. (2001). Biodegradable polymeric nanoparticles as drug delivery devices.Journal of controlled release, $70(1), 1-20$.

[157]Palvai, S., More, P., Mapara, N., \& Basu, S. (2015). Chimeric Nanoparticle: A Platform for Simultaneous Targeting of Phosphatidylinositol-3-Kinase Signaling and Damaging DNA in Cancer Cells. ACS Applied Materials \& Interfaces. Article ASAP

[158]Poon, C., He, C., Liu, D., Lu, K., \& Lin, W. (2015). Self-assembled nanoscale coordination polymers carrying oxaliplatin and gemcitabine for synergistic combination therapy of pancreatic cancer. Journal of Controlled Release, 201, 90-99.

[159] McRae Page, S., Henchey, E., Chen, X., Schneider, S., \& Emrick, T. (2014). Efficacy of PolyMPC-DOX Prodrugs in 4T1 Tumor-Bearing Mice. Molecular pharmaceutics, 11(5), 1715-1720.

[160]Pacardo, D. B., Ligler, F. S., \& Gu, Z. (2015). Programmable nanomedicine: synergistic and sequential drug delivery systems. Nanoscale, 7(8), 3381-3391.

[161] You, J. O., Guo, P., \& Auguste, D. T. (2013). A Drug-Delivery Vehicle Combining the Targeting and Thermal Ablation of HER2+ Breast-Cancer Cells with Triggered Drug Release. Angewandte Chemie International Edition, 52(15), 4141-4146.

[162] Kwon, H. J., Byeon, Y., Jeon, H. N., Cho, S. H., Han, H. D., \& Shin, B. C. (2015). Gold cluster-labeled thermosensitive liposmes enhance triggered drug release in the tumor microenvironment by a photothermal effect. Journal of Controlled Release, 216, 132-139.

[163]Zhou, S., Sha, H., Ke, X., Liu, B., Wang, X., \& Du, X. (2015). Combination drug release of smart cyclodextrin-gated mesoporous silica nanovehicles.Chemical Communications, 51(33), 7203-7206.

[164] Song, J., Im, K., Hwang, S., Hur, J., Nam, J., Ahn, G. O., Hwang, S., Kim, S., \& Park, N. (2015). DNA hydrogel delivery vehicle for light-triggered and synergistic cancer 
therapy. Nanoscale, 7(21), 9433-9437.

[165]Chen, W., Achazi, K., Schade, B., \& Haag, R. (2015). Charge-conversional and reduction-sensitive poly (vinyl alcohol) nanogels for enhanced cell uptake and efficient intracellular doxorubicin release. Journal of Controlled Release, 205, 15-24.

[166] Sun, W., Jiang, T., Lu, Y., Reiff, M., Mo, R., \& Gu, Z. (2014). Cocoon-Like selfdegradable DNA nanoclew for anticancer drug Delivery. Journal of the American Chemical Society, 136(42), 14722-14725.

[167]Mo, R., Jiang, T., \& Gu, Z. (2014). Enhanced anticancer efficacy by ATP-mediated liposomal drug delivery. Angewandte Chemie,126(23), 5925-5930.

[168]Ran Mo, Tianyue Jiang, Rocco DiSanto, Wanyi Tai, Zhen Gu. ATP-triggered anticancer drug delivery. Nature Communications, 2014; 5, 3364; 1-10.

[169] van Rijt, S. H., Bölükbas, D. A., Argyo, C., Datz, S., Lindner, M., Eickelberg, O., Königshoff, M., Bein, T., \& Meiners, S. (2015). Protease-mediated release of chemotherapeutics from mesoporous silica nanoparticles to ex vivo human and mouse lung tumors. ACS Nano, 9(3), 2377-2389.

[170]Zalba, S., Contreras, A. M., Haeri, A., ten Hagen, T. L., Navarro, I., Koning, G., \& Garrido, M. J. (2015). Cetuximab-oxaliplatin-liposomes for Epidermal Growth Factor receptor targeted chemotherapy of colorectal cancer. Journal of Controlled Release, 210:26-38.

[171] Okuda, T., Tominaga, K., \& Kidoaki, S. (2010). Time-programmed dual release formulation by multilayered drug-loaded nanofiber meshes. Journal of Controlled Release, 143(2), 258-264.

[172]Zhang, H., Wang, G., \& Yang, H. (2011). Drug delivery systems for differential release in combination therapy. Expert opinion on drug delivery, 8(2), 171-190

[173] Greco, F., \& Vicent, M. J. (2009). Combination therapy: opportunities and challenges for polymer-drug conjugates as anticancer nanomedicines.Advanced Drug Delivery Reviews, 61(13), 1203-1213.

[174]Narayanan, S., Mony, U., Vijaykumar, D. K., Koyakutty, M., Paul-Prasanth, B., \& Menon, D. (2015). Sequential release of Epigallocatechin gallate and Paclitaxel from PLGA-Casein core/shell nanoparticles sensitizes drug-resistant breast cancer cells. Nanomedicine: Nanotechnology, Biology and Medicine. 
[175]Patel, Nikhil M., Shinichi Nozaki, Nicholas H. Shortle, Poornima Bhat-Nakshatri, Thomas R. Newton, Susan Rice, Vasily Gelfanov et al. "Paclitaxel sensitivity of breast cancer cells with constitutively active NF-kappaB is enhanced by IkappaBalpha superrepressor and parthenolide." Oncogene 19, no. 36 (2000): 4159-4169.

[176] Sen, Triparna, Shuvojit Moulik, Anindita Dutta, Paromita Roy Choudhury, Aniruddha Banerji, Shamik Das, Madhumita Roy, and Amitava Chatterjee. "Multifunctional effect of epigallocatechin-3-gallate (EGCG) in downregulation of gelatinase-A (MMP-2) in human breast cancer cell line MCF-7." Life sciences84, no. 7 (2009): 194-204.

[177]Duong, H. T., Marquis, C. P., Whittaker, M., Davis, T. P., \& Boyer, C. (2011). Acid degradable and biocompatible polymeric nanoparticles for the potential codelivery of therapeutic agents. Macromolecules, 44(20), 8008-8019.

[178]Hu, S. H., Chen, S. Y., \& Gao, X. (2012). Multifunctional nanocapsules for simultaneous encapsulation of hydrophilic and hydrophobic compounds and on-demand release. ACS Nano, 6(3), 2558-2565.

[179]Tai, W., Mo, R., Lu, Y., Jiang, T., \& Gu, Z. (2014). Folding graft copolymer with pendant drug segments for co-delivery of anticancer drugs. Biomaterials,35(25), 71947203.

[180] Wang, W., Song, H., Zhang, J., Li, P., Li, C., Wang, C., Kong, D., \& Zhao, Q. (2015). An injectable, thermosensitive and multicompartment hydrogel for simultaneous encapsulation and independent release of a drug cocktail as an effective combination therapy platform. Journal of Controlled Release, 203, 57-66.

[181]Cho, S. K., \& Kwon, Y. J. (2012). Simultaneous gene transduction and silencing using stimuli-responsive viral/nonviral chimeric nanoparticles. Biomaterials, 33(11), 33163323.

[182] Niidome, T., \& Huang, L. (2002). Gene therapy progress and prospects: nonviral vectors. Gene Therapy, 9(24), 1647-1652.

[183] Yamamoto, Y., Lin, P. J., Beraldi, E., Zhang, F., Kawai, Y., Leong, J., Katsumi, H., Fazil, L., Fraser, R., Cullis, P. R., \& Gleave, M. E. (2015). siRNA lipid nanoparticle potently silence clusterin and delay progression when combined with androgen receptor co-targeting in enzalutamide resistant prostate cancer. Clinical Cancer Research, clincanres-0866. 
[184] Vijayanathan, V., Thomas, T., \& Thomas, T. J. (2002). DNA nanoparticles and development of DNA delivery vehicles for gene therapy. Biochemistry, 41(48), 1408514094.

[185]Creixell, M., \& Peppas, N. A. (2012). Co-delivery of siRNA and therapeutic agents using nanocarriers to overcome cancer resistance. Nano Today, 7(4), 367-379

[186]Zheng, C., Zheng, M., Gong, P., Deng, J., Yi, H., Zhang, P., Zhang, Y., Liu, P., Ma, Y., \& Cai, L. (2013). Polypeptide cationic micelles mediated co-delivery of docetaxel and siRNA for synergistic tumor therapy. Biomaterials, 34(13), 3431-3438.

[187] Y.B. Patil, S.K. Swaminathan, T. Sadhukha, L.Ma, J. Panyam, The use of nanoparticlemediated targeted gene silencing and drug delivery to overcome tumor drug resistance, Biomaterials 31 (2010) 358-365.

[188] Wu, H., Hait, W. N., \& Yang, J. M. (2003). Small interfering RNA-induced suppression of MDR1 (P-glycoprotein) restores sensitivity to multidrug-resistant cancer cells. Cancer Research, 63(7), 1515-1519.

[189]Yang, Jiyuan, and Jindřich Kopeček. "MACROMOLECULAR THERAPEUTICS.” Journal of controlled release: official journal of the Controlled Release Society 0 (2014): 288-303. PMC. Web. 14 Oct. 2015.

[190]Meng, H., Mai, W. X., Zhang, H., Xue, M., Xia, T., Lin, S., Wang, X., Zhao, Y., Ji, Z., Zink, J. I., \& Nel, A. E. (2013). Codelivery of an optimal drug/siRNA combination using mesoporous silica nanoparticles to overcome drug resistance in breast cancer in vitro and in vivo. ACS Nano, 7(2), 994-1005.

[191]M. Susa, A.K. Iyer, K. Ryu, E. Choy, F.J. Hornicek, H. Mankin, L. Milane, M.M. Amiji, Z. Duan, Inhibition of ABCB1 (MDR1) expression by an siRNA nanoparticulate delivery system to overcome drug resistance in osteosarcoma, PLoS One 5 (2010) e10764.

[192] Wang, W., \& El-Deiry, W. S. (2008). Restoration of p53 to limit tumor growth. Current Opinion in Oncology, 20(1), 90-96.

[193]Chang, T. C., Wentzel, E. A., Kent, O. A., Ramachandran, K., Mullendore, M., Lee, K. H., Feldmann, G., Yamakuchi, M., Ferlito, M., Lowenstein, C. J., Arking, D. E., Beer, M. A., Maitra, A., \& Mendell, J. T. (2007). Transactivation of miR-34a by p53 broadly influences gene expression and promotes apoptosis. Molecular Cell,26(5), 745-752.

[194]Xue, W., Dahlman, J. E., Tammela, T., Khan, O. F., Sood, S., Dave, A., Cai, W., Chirino, 
L. M., Yang, G. R., Bronson, R., Crowley, D. G., Sahaya, G., Schroeder, A., Langer, R., Anderson, D. G., \& Jacks, T. (2014). Small RNA combination therapy for lung cancer. Proceedings of the National Academy of Sciences of the United States of America, 111(34), E3553-E3561.

[195] May, J. P., \& Li, S. D. (2013). Hyperthermia-induced drug targeting. Expert Opinion on Drug Delivery, 10(4), 511-527.

[196] Chatterjee, D. K., Diagaradjane, P., \& Krishnan, S. (2011). Nanoparticle-mediated hyperthermia in cancer therapy. Therapeutic Delivery, 2(8), 1001-1014.

[197]Hong, C., Kang, J., Kim, H., \& Lee, C. (2012). Photothermal properties of inorganic nanomaterials as therapeutic agents for cancer thermotherapy. Journal of Nanoscience and Nanotechnology, 12(5), 4352-4355.

[198] Yi, X., Yang, K., Liang, C., Zhong, X., Ning, P., Song, G., Wang, D., Ge, C., Chen, C., Chai, C., \& Liu, Z. (2015). Imaging-Guided Combined Photothermal and Radiotherapy to Treat Subcutaneous and Metastatic Tumors Using Iodine-131-Doped Copper Sulfide Nanoparticles. Advanced Functional Materials, 25(29), 4689-4699.

[199]Park, J., Park, J., Ju, E. J., Park, S. S., Choi, J., Lee, J. H., Shin, S. H., Ko, E. J., Park, I., Kim, C., Hwang, J. J., Lee, J. S., Song, S. Y., Jeong, S. Y \& Choi, E. K. (2015). Multifunctional hollow gold nanoparticles designed for triple combination therapy and CT imaging. Journal of Controlled Release, 207, 77-85.

[200] Kim, Y. K., Na, H. K., Kim, S., Jang, H., Chang, S. J., \& Min, D. H. (2015). One-Pot Synthesis of Multifunctional Au@ Graphene Oxide Nanocolloid Core@ Shell Nanoparticles for Raman Bioimaging, Photothermal, and Photodynamic Therapy. Small, 11: $2527-2535$

[201]Zhou, L., Dong, K., Chen, Z., Ren, J., \& Qu, X. (2015). Near-infrared absorbing mesoporous carbon nanoparticle as an intelligent drug carrier for dual-triggered synergistic cancer therapy. Carbon, 82, 479-488.

[202]Wu, L., Wu, M., Zeng, Y., Zhang, D., Zheng, A., Liu, X., \& Liu, J. (2015). Multifunctional PEG modified DOX loaded mesoporous silica nanoparticle@ CuS nanohybrids as photo-thermal agent and thermal-triggered drug release vehicle for hepatocellular carcinoma treatment. Nanotechnology, 26(2), 025102.

[203]Song, X., Liang, C., Gong, H., Chen, Q., Wang, C., \& Liu, Z. (2015). 
PhotosensitizerConjugated Albumin- Polypyrrole nanoparticles for imaging-guided in vivo photodynamic/photothermal therapy. Small, 11: 3932-3941

[204] Weissleder, R. (2001). A clearer vision for in vivo imaging. Nature Biotechnology, 19(4), 316-316.

[205] Sailor, M. J., \& Park, J. H. (2012). Hybrid nanoparticles for detection and treatment of cancer. Advanced Materials, 24(28), 3779-3802.

[206] Melancon, M. P., Zhou, M. I. N., \& Li, C. (2011). Cancer theranostics with near-infrared light-activatable multimodal nanoparticles. Accounts of chemical research, 44(10), 947956.

[207] Greish, K. (2007). Enhanced permeability and retention of macromolecular drugs in solid tumors: a royal gate for targeted anticancer nanomedicines. Journal of Drug Targeting, 15(7-8), 457-464.

[208] Matsumura, Y., Oda, T., \& Maeda, H. (1987). [General mechanism of intratumor accumulation of macromolecules: advantage of macromolecular therapeutics]. Gan to kagaku ryoho. Cancer \& chemotherapy, 14(3 Pt 2), 821-829.

[209] Cobley, C. M., Chen, J., Cho, E. C., Wang, L. V., \& Xia, Y. (2011). Gold nanostructures: a class of multifunctional materials for biomedical applications. Chemical Society Reviews, 40(1), 44-56.

[210]Prodan, E., Nordlander, P., \& Halas, N. J. (2003). Electronic structure and optical properties of gold nanoshells. Nano Letters, 3(10), 1411-1415.

[211]Chen, H., Shao, L., Li, Q., \& Wang, J. (2013). Gold nanorods and their plasmonic properties. Chemical Society Reviews, 42(7), 2679-2724.

[212] Skrabalak, S. E., Chen, J., Sun, Y., Lu, X., Au, L., Cobley, C. M., \& Xia, Y. (2008). Gold nanocages: synthesis, properties, and applications. Accounts of Chemical Research, 41(12), 1587-1595.

[213]Zhou, J., Ralston, J., Sedev, R., \& Beattie, D. A. (2009). Functionalized gold nanoparticles: synthesis, structure and colloid stability. Journal of Colloid and Interface Science, 331(2), 251-262.

[214] Khlebtsov, N., \& Dykman, L. (2011). Biodistribution and toxicity of engineered gold nanoparticles: a review of in vitro and in vivo studies. Chemical Society Reviews, 40(3), 1647-1671. 
[215]Liu, H., Chen, D., Li, L., Liu, T., Tan, L., Wu, X., \& Tang, F. (2011). Multifunctional gold nanoshells on silica nanorattles: a platform for the combination of photothermal therapy and chemotherapy with low systemic toxicity. Angewandte Chemie International Edition, 123(4), 921-925.

[216]Lee, S. M., Park, H., \& Yoo, K. H. (2010). Synergistic cancer therapeutic effects of locally delivered drug and heat using multifunctional nanoparticles. Advanced Materials, 22(36), 4049-4053.

[217] You, J., Shao, R., Wei, X., Gupta, S., \& Li, C. (2010). Near-infrared light triggers release of paclitaxel from biodegradable microspheres: photothermal effect and enhanced antitumor activity. Small, 6(9), 1022-1031.

[218] You, J., Zhang, G., \& Li, C. (2010). Exceptionally high payload of doxorubicin in hollow gold nanospheres for near-infrared light-triggered drug release. ACS Nano, 4(2), 10331041.

[219] You, J., Zhang, R., Zhang, G., Zhong, M., Liu, Y., Van Pelt, C. S., Liang, D., Wei, W., Sood, A. K., \& Li, C. (2012). Photothermal-chemotherapy with doxorubicin-loaded hollow gold nanospheres: A platform for near-infrared light-trigged drug release. Journal of Controlled Release, 158(2), 319-328.

[220] You, J., Zhang, P., Hu, F., Du, Y., Yuan, H., Zhu, J., Wang, Z., Zhou, J., \& Li, C. (2014). Near-infrared light-sensitive liposomes for the enhanced photothermal tumor treatment by the combination with chemotherapy. Pharmaceutical research,31(3), 554-565.

[221]Monem, A. S., Elbialy, N., \& Mohamed, N. (2014). Mesoporous silica coated gold nanorods loaded doxorubicin for combined chemo-photothermal therapy. International Journal of Pharmaceutics, 470(1), 1-7.

[222] Shi, P., Qu, K., Wang, J., Li, M., Ren, J., \& Qu, X. (2012). pH-responsive NIR enhanced drug release from gold nanocages possesses high potency against cancer cells. Chemical Communications, 48(61), 7640-7642.

[223]Gong, H., Peng, R., \& Liu, Z. (2013). Carbon nanotubes for biomedical imaging: the recent advances. Advanced Drug Delivery Reviews, 65(15), 1951-1963.

[224] Yang, K., Feng, L., Shi, X., \& Liu, Z. (2013). Nano-graphene in biomedicine: theranostic applications. Chemical Society Reviews, 42(2), 530-547.

[225]Lay, C. L., Liu, J., \& Liu, Y. (2011). Functionalized carbon nanotubes for anticancer drug 
delivery. Expert review of Medical Devices, 8(5), 561-566.

[226]Liu, Z., Fan, A. C., Rakhra, K., Sherlock, S., Goodwin, A., Chen, X., Yang, Q., Felsher, D. W., \& Dai, H. (2009). Supramolecular stacking of doxorubicin on carbon nanotubes for in vivo cancer therapy. Angewandte Chemie International Edition, 48(41), 76687672.

[227]Liu, Y., Zhao, Y., Sun, B., \& Chen, C. (2012). Understanding the toxicity of carbon nanotubes. Accounts of Chemical Research, 46(3), 702-713.

[228]Xu, G., Liu, S., Niu, H., Lv, W., \& Wu, R. A. (2014). Functionalized mesoporous carbon nanoparticles for targeted chemo-photothermal therapy of cancer cells under nearinfrared irradiation. RSC Advances, 4(64), 33986-33997.

[229] Wang, L., Zhang, M., Zhang, N., Shi, J., Zhang, H., Li, M., Lu, C., \& Zhang, Z. (2011). Synergistic enhancement of cancer therapy using a combination of docetaxel and photothermal ablation induced by single-walled carbon nanotubes. International Journal of Nanomedicine, 6, 2641

[230]Zhang, W., Guo, Z., Huang, D., Liu, Z., Guo, X., \& Zhong, H. (2011). Synergistic effect of chemo-photothermal therapy using PEGylated graphene oxide. Biomaterials, 32(33), 8555-8561.

[231]Qin, X. C., Guo, Z. Y., Liu, Z. M., Zhang, W., Wan, M. M., \& Yang, B. W. (2013). Folic acid-conjugated graphene oxide for cancer targeted chemo-photothermal therapy. Journal of Photochemistry and Photobiology B: Biology,120, 156-162.

[232]Dolmans, D. E., Fukumura, D., \& Jain, R. K. (2003). Photodynamic therapy for cancer. Nature Reviews Cancer, 3(5), 380-387.

[233] Ackroyd, R., Kelty, C., Brown, N., \& Reed, M. (2001). The history of photodetection and photodynamic therapyII. Photochemistry and photobiology,74(5), 656-669.

[234] Chang, J. E., Yoon, I. S., Sun, P. L., Yi, E., Jheon, S., \& Shim, C. K. (2014). Anticancer efficacy of photodynamic therapy with hematoporphyrin-modified, doxorubicin-loaded nanoparticles in liver cancer. Journal of Photochemistry and Photobiology B: Biology, 140, 49-56.

[235] Conte, C., Ungaro, F., Maglio, G., Tirino, P., Siracusano, G., Sciortino, M. T., Leone, N., Palma, G., Barbieri, A., Arra, C., Mazzaglia, A., \& Quaglia, F. (2013). Biodegradable core-shell nanoassemblies for the delivery of docetaxel and $\mathrm{Zn}$ (II)-phthalocyanine 
inspired by combination therapy for cancer. Journal of Controlled Release, 167(1), 40-52. [236]Zhang, W., Li, Y., Sun, J. H., Tan, C. P., Ji, L. N., \& Mao, Z. W. (2015). Supramolecular self-assembled nanoparticles for chemo-photodynamic dual therapy against cisplatin resistant cancer cells. Chemical Communications,51(10), 1807-1810.

[237]Deng, X., Liang, Y., Peng, X., Su, T., Luo, S., Cao, J., Gu, Z., \& He, B. (2015). A facile strategy to generate polymeric nanoparticles for synergistic chemo-photodynamic therapy. Chem. Commun. 51(20):4271-4

[238]Peng, C. L., Shieh, M. J., Tsai, M. H., Chang, C. C., \& Lai, P. S. (2008). Self-assembled star-shaped chlorin-core poly ( $\varepsilon$-caprolactone)-poly (ethylene glycol) diblock copolymer micelles for dual chemo-photodynamic therapies. Biomaterials, 29(26), 3599-3608.

[239]Peng, C. L., Lai, P. S., Lin, F. H., Wu, S. Y. H., \& Shieh, M. J. (2009). Dual chemotherapy and photodynamic therapy in an HT-29 human colon cancer xenograft model using SN-38-loaded chlorin-core star block copolymer micelles. Biomaterials, 30(21), 3614-3625.

[240]He, C., Liu, D., \& Lin, W. (2015). Self-assembled core-shell nanoparticles for combined chemotherapy and photodynamic therapy of resistant head and neck cancers. ACS Nano, 9(1), 991-1003.

[241] Shi, J., Liu, Y., Wang, L., Gao, J., Zhang, J., Yu, X., Ma R, Liu R, \& Zhang, Z. (2014). A tumoral acidic pH-responsive drug delivery system based on a novel photosensitizer (fullerene) for in vitro and in vivo chemo-photodynamic therapy. Acta biomaterialia, 10(3), 1280-1291.

[242] Guo, X., Ding, R., Zhang, Y., Ye, L., Liu, X., Chen, C., Zhang, Z., \& Zhang, Y. (2014). Dual Role of Photosensitizer and Carrier Material of Fullerene in Micelles for ChemoPhotodynamic Therapy of Cancer. Journal of Pharmaceutical Sciences,103(10), 32253234.

[243] Setua, S., Ouberai, M., Piccirillo, S. G., Watts, C., \& Welland, M. (2014). Cisplatintethered gold nanospheres for multimodal chemo-radiotherapy of glioblastoma. Nanoscale, 6(18), 10865-10873.

[244]Xu, C., Zheng, Y., Gao, W., Xu, J., Zuo, G., Chen, Y., Zhao, M., Li, J., Song, J., Zhang, N., Wang, Z., Zhao, H., \& Mei, Z. (2015). Magnetic hyperthermia ablation of tumors using injectable Fe3O4/calcium phosphate cement. ACS Applied Materials \& Interfaces, 
7(25), 13866-13875.

[245]Di Corato, R., Béalle, G., Kolosnjaj-Tabi, J., Espinosa, A., Clément, O., Silva, A. K., Ménager, C.,\& Wilhelm, C. (2015). Combining magnetic hyperthermia and photodynamic therapy for tumor ablation with photoresponsive magnetic liposomes. ACS Nano, 9(3), 2904-2916.

[246]Zhang, E., Kircher, M. F., Koch, M., Eliasson, L., Goldberg, S. N., \& Renström, E. (2014). Dynamic magnetic fields remote-control apoptosis via nanoparticle rotation. ACS Nano, 8(4), 3192-3201.

[247] Shvedova, A. A., Kagan, V. E., \& Fadeel, B. (2010). Close encounters of the small kind: adverse effects of man-made materials interfacing with the nano-cosmos of biological systems. Annual Review of Pharmacology and Toxicology, 50, 63-88. 